\title{
Hematite Nanoparticles-Modified Electrode Based Electrochemical Sensing Platform for Dopamine
}

\author{
Khosro Zangeneh Kamali, ${ }^{1}$ Pandikumar Alagarsamy, ${ }^{1}$ Nay Ming Huang, \\ Boon Hoong Ong, ${ }^{2}$ and Hong Ngee Lim $^{3}$ \\ ${ }^{1}$ Low Dimensional Materials Research Centre, Department of Physics, Faculty of Science, University of Malaya, \\ 50603 Kuala Lumpur, Malaysia \\ ${ }^{2}$ Nanotechnology \& Catalysis Research Center, Institute of Graduate Studies, University of Malaya, \\ Level 3, Block A, 50603 Kuala Lumpur, Malaysia \\ ${ }^{3}$ Department of Chemistry, Faculty of Science, University Putra Malaysia, 43400 Serdang, Selangor, Malaysia
}

Correspondence should be addressed to Pandikumar Alagarsamy; pandikumarinbox@gmail.com and Nay Ming Huang; huangnayming@um.edu.my

Received 16 April 2014; Revised 18 June 2014; Accepted 26 June 2014; Published 21 July 2014

Academic Editor: Liqiang Jing

Copyright (C) 2014 Khosro Zangeneh Kamali et al. This is an open access article distributed under the Creative Commons Attribution License, which permits unrestricted use, distribution, and reproduction in any medium, provided the original work is properly cited.

Hematite $\left(\alpha-\mathrm{Fe}_{2} \mathrm{O}_{3}\right)$ nanoparticles were synthesized by the solid transformation of ferrous hydroxide and ferrihydrite in hydrothermal condition. The as-prepared $\alpha-\mathrm{Fe}_{2} \mathrm{O}_{3}$ nanoparticles were characterized by UV-vis, PL, XRD, Raman, TEM, AFM, FESEM, and EDX analysis. The experimental results indicated the formation of uniform hematite nanoparticles with an average size of $45 \mathrm{~nm}$ and perfect crystallinity. The electrochemical behavior of a GC/ $\alpha-\mathrm{Fe}_{2} \mathrm{O}_{3}$ electrode was studied using CV and EIS techniques with an electrochemical probe, $\left[\mathrm{Fe}(\mathrm{CN})_{6}\right]^{3-/ 4-}$ redox couple. The electrocatalytic activity was investigated toward DA oxidation in a phosphate buffer solution ( $\mathrm{pH}$ 6.8) by varying different experimental parameters. The chronoamperometric study showed a linear response in the range of $0-2 \mu \mathrm{M}$ with $\mathrm{LoD}$ of $1.6 \mu \mathrm{M}$ for DA. Square wave voltammetry showed a linear response in the range of $0-35 \mu \mathrm{M}$ with $\mathrm{LoD}$ of $236 \mathrm{nM}$ for $\mathrm{DA}$.

\section{Introduction}

Hematite $\left(\alpha-\mathrm{Fe}_{2} \mathrm{O}_{3}\right)$ is thermodynamically the most stable iron oxide with $\mathrm{n}$-type semiconductor properties [1]. Its stability, favorable band-gap (2.1-2.2 eV), and low cost make $\alpha-\mathrm{Fe}_{2} \mathrm{O}_{3}$ one of the most promising materials, and it is used in catalysis, electrocatalysis, photocatalysis, electrochemical sensors, and gas sensors [2-5]. The lower band-gap of hematite compared to titanium dioxide enables this material to absorb light in the visible range [6]. The properties of $\alpha$ $\mathrm{Fe}_{2} \mathrm{O}_{3}$ are highly affected by the morphology, crystallite size, and crystallinity of the material. Many synthetic methods for preparing $\alpha-\mathrm{Fe}_{2} \mathrm{O}_{3}$ have been investigated. These processes involve the use of a surfactant, very high temperature, corrosive, toxic, or expensive raw materials, or a long synthesizing period [7-9]. Discovering a low-cost and facile method to synthesize $\alpha-\mathrm{Fe}_{2} \mathrm{O}_{3}$ with excellent quality and desirable properties has always been a challenge for scientists. In this work, we describe a low-cost, facile method of synthesizing nanosized $\alpha-\mathrm{Fe}_{2} \mathrm{O}_{3}$ particles.

Dopamine (DA) is a neurotransmitter that plays an important role in the brain and nervous system. DA is measured in the body using electrochemical sensors for monitoring HIV infection and the diagnosis of Parkinson's disease. The importance of DA in the nervous system has resulted in the fabrication of electrochemical sensors for its detection $[6,7]$. Some work has been done to investigate the performance of $\alpha-\mathrm{Fe}_{2} \mathrm{O}_{3}$-modified electrode in supercapacitors, but few studies have been done on the electrochemical properties of $\alpha-\mathrm{Fe}_{2} \mathrm{O}_{3}$ for electrochemical sensors [4].

The overall objective of the present study was the improvement of the sensitivity toward the electrochemical detection of DA by using an $\alpha-\mathrm{Fe}_{2} \mathrm{O}_{3}$ nanoparticle-modified electrode $\left(\mathrm{GC} / \alpha-\mathrm{Fe}_{2} \mathrm{O}_{3}\right)$. Initially, $\alpha-\mathrm{Fe}_{2} \mathrm{O}_{3}$ nanoparticles 


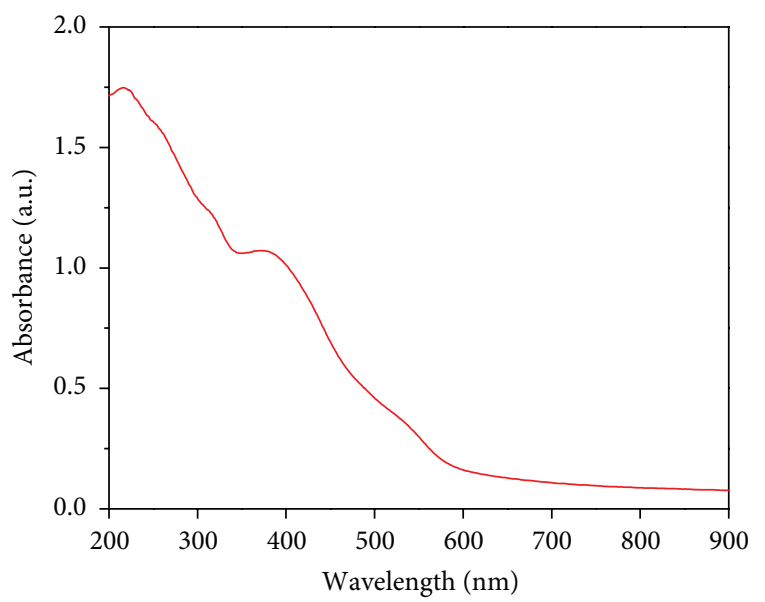

(a)

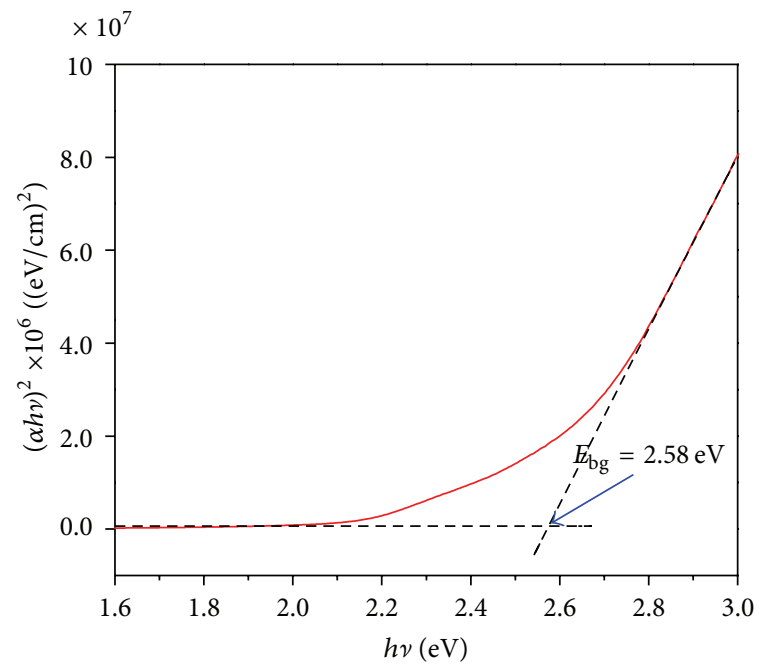

(c)

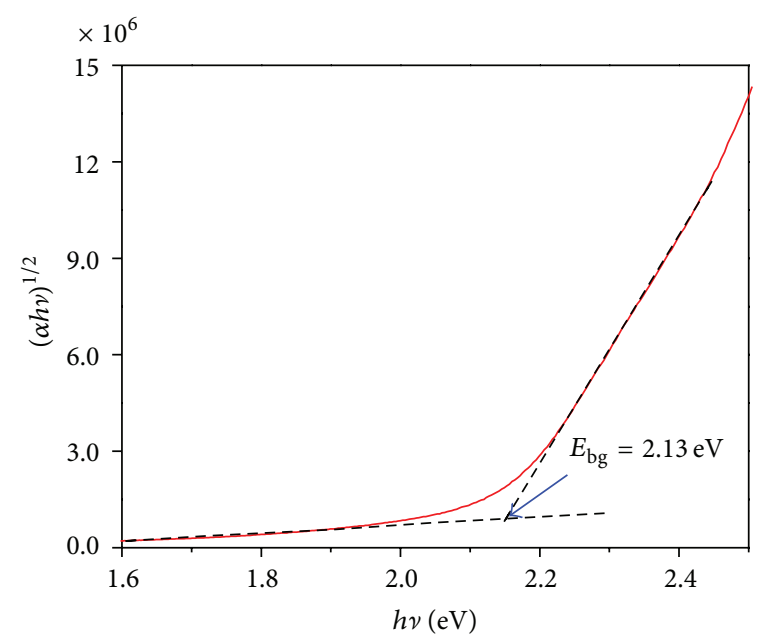

(b)

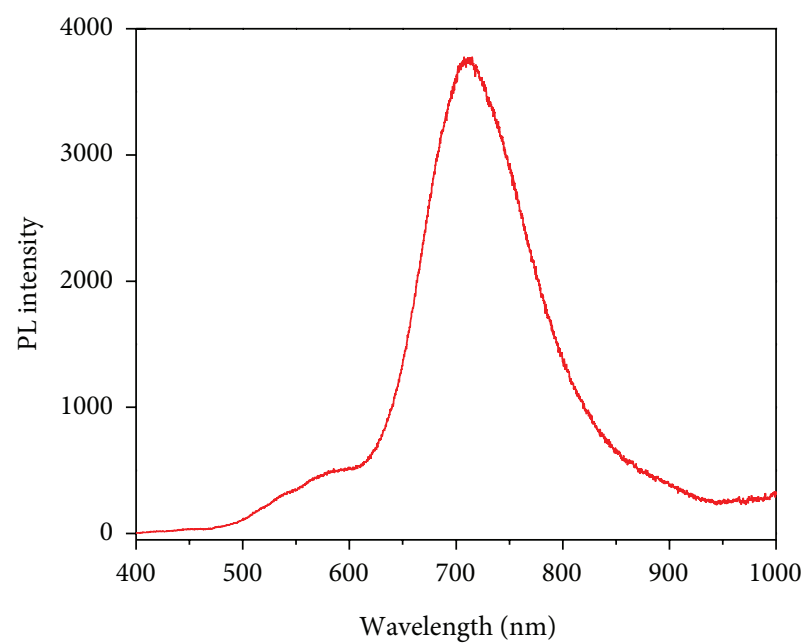

(d)

FIGURE 1: (a) UV-visible absorption spectrum of colloidal $\alpha-\mathrm{Fe}_{2} \mathrm{O}_{3}$ nanoparticles. Plots of (b) $(\alpha h \nu)^{2}$ versus $h \nu$ obtained due to direct transition and (c) $(\alpha h v)^{1 / 2}$ versus $h v$ obtained due to indirect transition of $\alpha-\mathrm{Fe}_{2} \mathrm{O}_{3}$ nanoparticles and (d) PL spectrum of colloidal $\alpha$-Fe $\mathrm{O}_{2} \mathrm{O}_{3}$ nanoparticles.

were prepared using a simple hydrothermal method and then used to fabricate the sensor electrode. A ferricyanide redox couple was used as a marker to probe the $\alpha-\mathrm{Fe}_{2} \mathrm{O}_{3}$ nanoparticle-modified electrode interface with a tunable kinetic barrier. The GC/ $\alpha-\mathrm{Fe}_{2} \mathrm{O}_{3}$ electrode showed a better electrocatalytic response toward DA oxidation compared to bare GC electrode. The square wave voltammetry and chronoamperometric techniques were also employed for the detection of DA and showed excellent selectivity and sensitivity.

\section{Experimental Methods}

2.1. Materials. Chemical reagents such as ferrous chloride tetrahydrate $\left(\mathrm{FeCl}_{2} \cdot 6 \mathrm{H}_{2} \mathrm{O}\right)$, ferric chloride hexahydrate $\left(\mathrm{FeCl}_{3} \cdot 6 \mathrm{H}_{2} \mathrm{O}\right)$, dopamine (DA), and ammonia solution $\left(\mathrm{NH}_{3}\right)$ were purchased from Merck and used as received.
Sodium dihydrogen phosphate $\left(\mathrm{NaH}_{2} \mathrm{PO}_{4}\right)$ and disodium hydrogen phosphate $\left(\mathrm{Na}_{2} \mathrm{HPO}_{4}\right)$ were received from system and used without further purification. All the other chemicals used in this investigation were of analytical grade, unless otherwise stated, and highly pure deionized water was used throughout this experiment. A stock solution of DA was freshly prepared daily by dissolving it into a suitable amount of deionized water prior to use. Electrolyte and phosphate buffer solutions at different $\mathrm{pH}$ values were prepared by mixing stock solutions of $0.1 \mathrm{M} \mathrm{NaH}_{2} \mathrm{PO}_{4}$ and $0.1 \mathrm{M} \mathrm{Na}_{2} \mathrm{HPO}_{4}$, and then the required $\mathrm{pH}$ values were adjusted by using $0.1 \mathrm{M}$ $\mathrm{HCl}$ and $0.1 \mathrm{M} \mathrm{NaOH}$.

2.2. Synthesis of $\alpha-\mathrm{Fe}_{2} \mathrm{O}_{3}$ Nanoparticles. The $\alpha-\mathrm{Fe}_{2} \mathrm{O}_{3}$ nanoparticles were prepared as follows. Typically, $235 \mathrm{mg}$ of $\mathrm{FeCl}_{3} \cdot 6 \mathrm{H}_{2} \mathrm{O}$ and $87 \mathrm{mg}$ of $\mathrm{FeCl}_{2} \cdot 4 \mathrm{H}_{2} \mathrm{O}$ were dissolved into $300 \mathrm{~mL}$ of deionized water and stirred for $10 \mathrm{~min}$. Further, 
a $25 \%$ ammonia solution was dropwise added to the above reaction mixture until the $\mathrm{pH}$ of the attained solution was 10. The reaction mixture was vigorously stirred for $1 \mathrm{~h}$ at room temperature. The sample was gathered by repeated centrifugation (6000 rpm for $2 \mathrm{~min}$ ) and washed with $100 \mathrm{~mL}$ of deionized water; this procedure was repeated three times, and it was redispersed into the deionized water. Further, the solution was poured into a $50 \mathrm{~mL}$ Teflon-lined autoclave and subjected to a hydrothermal process at $180^{\circ} \mathrm{C}$ for $12 \mathrm{~h}$. Finally, the resulting brownish-orange color precipitate was centrifuged, washed several times with water, and then dried in a hot air oven at $100^{\circ} \mathrm{C}$ to completely remove the moisture.

2.3. Characterization Techniques. The UV-visible absorption spectrum of the $\alpha-\mathrm{Fe}_{2} \mathrm{O}_{3}$ nanoparticles in the $190-900 \mathrm{~nm}$ spectral range was recorded using a Thermo Scientific Evolution-300 UV-vis absorption spectrophotometer. The PL spectrum was acquired from a Renishaw inVia 2000 system with a laser emitting at $325 \mathrm{~nm}$. The phase identification was recorded by using a Siemens-D5000 X-ray diffractometer with copper $\mathrm{K} \alpha$ radiation $(\lambda=1.5418 \AA)$ at a scan rate of $0.02^{\circ} / \mathrm{s}$. The surface morphology and elemental composition of the $\alpha-\mathrm{Fe}_{2} \mathrm{O}_{3}$ nanoparticles were examined using a JEOL field emission scanning electron microscope operated at $10 \mathrm{kV}$. The surface topography and roughness of the thin film were studied using Agilent's atomic force microscope (AFM) in AC mode. The size and shape of the obtained $\alpha-\mathrm{Fe}_{2} \mathrm{O}_{3}$ nanoparticles were studied using a JEOL JEM-2100F high resolution transmission electron microscope.

2.4. Electrochemical Studies. An $\alpha-\mathrm{Fe}_{2} \mathrm{O}_{3}$ nanoparticle-modified glassy carbon electrode $\left(\mathrm{GC} / \alpha-\mathrm{Fe}_{2} \mathrm{O}_{3}\right)$ was fabricated by dispersing $1 \mathrm{mg}$ of the synthesized $\alpha-\mathrm{Fe}_{2} \mathrm{O}_{3}$ nanoparticles in $1 \mathrm{~mL}$ of deionized water and then sonicating them for $30 \mathrm{~min}$ to ensure a homogeneous dispersion. A $5 \mu \mathrm{L}$ volume of the colloidal $\alpha-\mathrm{Fe}_{2} \mathrm{O}_{3}$ solution was cast on a glassy carbon electrode and then dried in a hot air oven at $65^{\circ} \mathrm{C}$ for $1 \mathrm{~h}$. This $\mathrm{GC} / \alpha-\mathrm{Fe}_{2} \mathrm{O}_{3} \mathrm{NP}$-modified electrode was used for the electrocatalytic oxidation of dopamine. All the electrochemical measurements were carried out using a VersaSTAT-3 electrochemical analyzer (Princeton Applied Research, USA) with a conventional three-electrode system under a nitrogen atmosphere at room temperature $\left(27^{\circ} \mathrm{C}\right)$. The $\alpha-\mathrm{Fe}_{2} \mathrm{O}_{3}$ nanoparticle-modified GC electrode, platinum wire, and saturated calomel electrode were used as the working, counter, and reference electrodes, respectively. A $0.1 \mathrm{M}$ phosphate buffer solution (PBS) $(\mathrm{pH}=6.8)$ was used as the supporting electrolyte. All the potentials are quoted against the saturated calomel electrode unless otherwise mentioned.

\section{Results and Discussion}

3.1. Optical Properties of $\alpha-\mathrm{Fe}_{2} \mathrm{O}_{3}$ Nanoparticles. The UVvisible absorption spectrum for the colloidal $\alpha-\mathrm{Fe}_{2} \mathrm{O}_{3}$ solution was recorded and is shown in Figure 1(a). The $\alpha$ $\mathrm{Fe}_{2} \mathrm{O}_{3}$ nanoparticles exhibit strong absorption in the range of

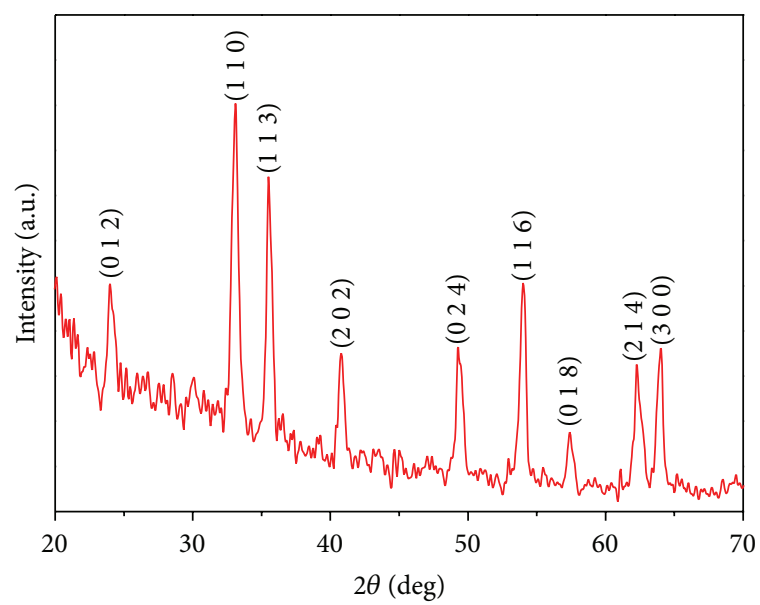

FIGURE 2: X-ray diffraction pattern observed for as-prepared $\alpha$ $\mathrm{Fe}_{2} \mathrm{O}_{3}$ nanoparticles.

200-400 $\mathrm{nm}$ in the UV region and weak absorption at 400$800 \mathrm{~nm}$ of the visible region. The two types of optical absorptions in the UV and visible regions are mainly attributed to the two kinds of electronic transition mechanisms. The former is due to the contribution of the direct charge transition of $\mathrm{O}_{2}{ }^{-} 2 \mathrm{p} \rightarrow \mathrm{Fe}^{3+} 3 \mathrm{~d}$ (UV absorption), and the latter originates from the indirect charge transition of $\mathrm{Fe}^{3+} 3 \mathrm{~d} \rightarrow 3 \mathrm{~d}$ (visible absorption) [8-10]. The band-gap energy $\left(E_{\mathrm{bg}}\right)$ value of the prepared $\alpha-\mathrm{Fe}_{2} \mathrm{O}_{3}$ nanoparticles was derived from the relationship between the absorption coefficient and the incident photon energy of the $\alpha-\mathrm{Fe}_{2} \mathrm{O}_{3}$ nanoparticles using Tauc's plot method [11, 12]. Consider

$$
\alpha=\frac{A\left(h v-E_{\mathrm{bg}}\right)^{n}}{h v},
$$

where $\alpha$ is the absorption coefficient, $E_{\mathrm{bg}}$ is the band-gap energy, and $A$ is the absorption constant. The absorption coefficient $(\alpha)$ was determined from the equation $\alpha=(2.303 \times$ $\left.10^{3}\right)(A) / L$ by using the measured absorbance $(A)$ and optical path length $(L)(1 \mathrm{~cm})$. The $n$ is equal to $1 / 2$ and 2 for allowed direct and allowed indirect transitions, respectively. By extrapolating the linear region in the plots of $(\alpha h \nu)^{n}$ versus $h v$, the band-gap energy values were obtained for the $\alpha-\mathrm{Fe}_{2} \mathrm{O}_{3}$ nanoparticles (Figures 1(b) and 1(c)). The calculated bandgap energy values of $2.58 \mathrm{eV}$ and $2.13 \mathrm{eV}$ are due to the allowed direct transition and allowed indirect transition, respectively, for the $\alpha-\mathrm{Fe}_{2} \mathrm{O}_{3}$ nanoparticles. This observed $E_{\mathrm{bg}}$ value is slightly higher and blue shifted compared to the results of previous reports because of the quantum size confinement in the nanoparticles. The photoluminescence spectrum of the $\alpha$ $\mathrm{Fe}_{2} \mathrm{O}_{3}$ nanoparticles was recorded using excitation by $325 \mathrm{~nm}$ laser irradiation and is shown in Figure 1(d). The broad and intense PL peak at $\sim 710 \mathrm{~nm}$ and shoulder peak at $590 \mathrm{~nm}$ are due to the band-edge emission of the $\alpha-\mathrm{Fe}_{2} \mathrm{O}_{3}$ nanoparticles, which correspond to the band-gap energies of 1.75 and $2.1 \mathrm{eV}$ for indirect and direct transitions. 


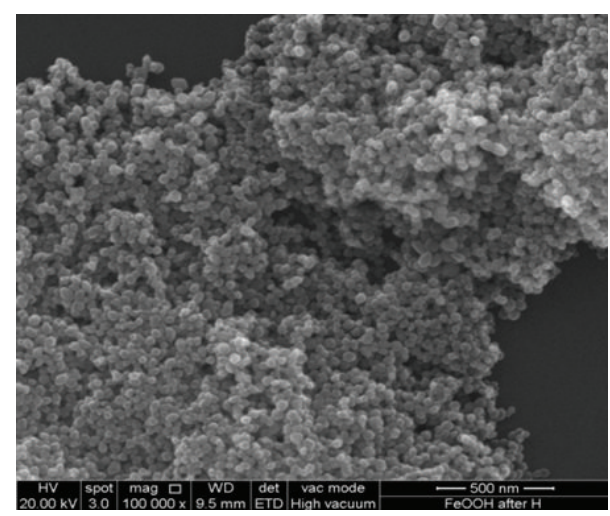

(a)

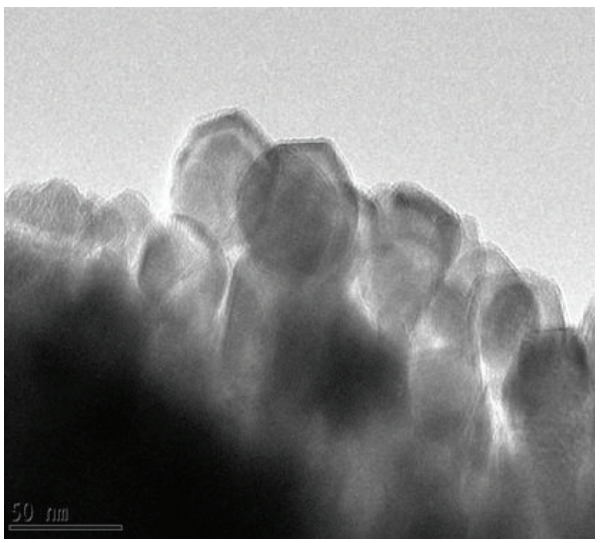

(c)

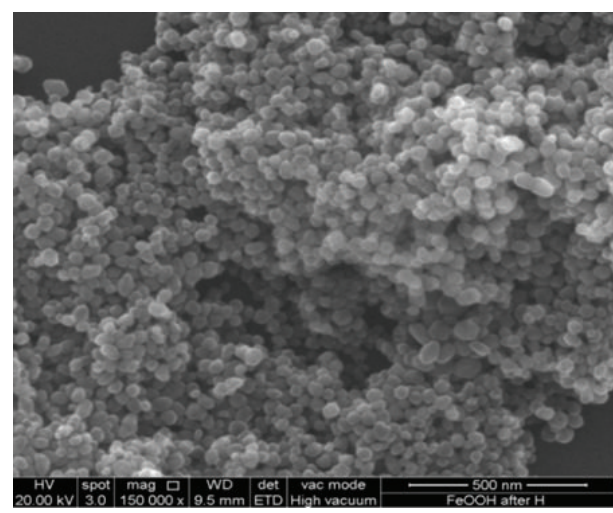

(b)

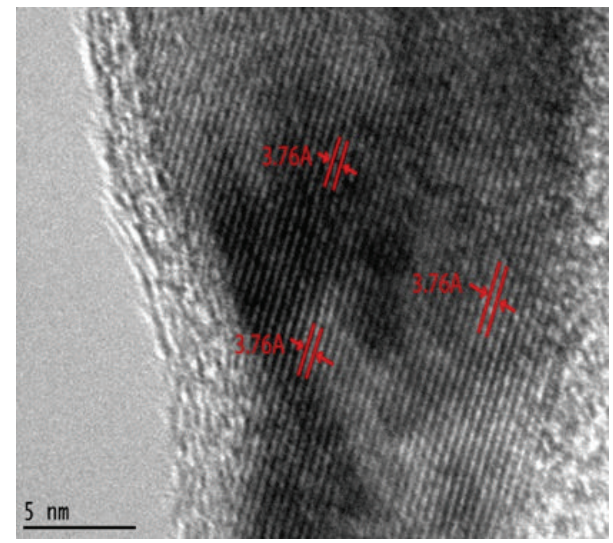

(d)

FIgURE 3: (a)-(b) FESEM and (c)-(d) HRTEM images of as-prepared $\alpha-\mathrm{Fe}_{2} \mathrm{O}_{3}$ nanoparticles.

3.2. XRD Analysis of $\alpha-\mathrm{Fe}_{2} \mathrm{O}_{3}$ Nanoparticles. The typical Xray diffraction peaks observed for the synthesized $\alpha-\mathrm{Fe}_{2} \mathrm{O}_{3}$ nanoparticles (Figure 2 ) at $2 \theta$ values of $24^{\circ}, 33^{\circ}, 35^{\circ}, 41^{\circ}, 49^{\circ}$, $54^{\circ}, 57^{\circ}, 62^{\circ}$, and $64^{\circ}$ correspond to the (0 12$)$, ( 1110$),\left(\begin{array}{lll}1 & 1 & 3\end{array}\right)$, (2 0 2 2$),\left(\begin{array}{lll}0 & 2 & 4\end{array}\right),\left(\begin{array}{lll}1 & 1 & 6\end{array}\right),\left(\begin{array}{lll}0 & 1 & 8\end{array}\right),\left(\begin{array}{lll}2 & 1 & 4\end{array}\right)$, and (3 000$)$ planes of the $\alpha-\mathrm{Fe}_{2} \mathrm{O}_{3}$ nanoparticles, respectively $[2,9,13]$. The absence of diffraction peaks due to $\mathrm{Fe}(\mathrm{OH})_{2}$ and $\mathrm{Fe}(\mathrm{OH})_{3}$ indicates the complete transformation of these hydroxides to hematite during the hydrothermal process. The crystallite size was calculated to be $\sim 40 \mathrm{~nm}$ for hematite particles using Scherrer's equation [13].

3.3. Morphological Studies of $\alpha-\mathrm{Fe}_{2} \mathrm{O}_{3}$ Nanoparticles. Figures $3(\mathrm{a})$ and 3(b) show FESEM images of the as-prepared $\alpha$ $\mathrm{Fe}_{2} \mathrm{O}_{3}$ nanoparticles, which are composed of uniform monodispersed hematite nanoparticles. The corresponding TEM image (Figure 3(c)) further demonstrates that the obtained nanoparticles have a homogeneous size with a diameter of $\sim$ $40 \mathrm{~nm}$, which is in good agreement with that calculated from Scherrer's equation. The lattice resolved high-magnification TEM image (Figure 3(d)) shows a lattice fringe distance of approximately $\sim 0.368 \mathrm{~nm}$, which corresponds to the $\left(\begin{array}{lll}0 & 1 & 2\end{array}\right)$ plane of the hematite nanoparticles.

In order to study the surface morphology of the $\alpha$ $\mathrm{Fe}_{2} \mathrm{O}_{3}$ nanoparticle-modified electrode, AFM images were recorded, and their corresponding angle view (3D) and top view (2D) images are shown in Figure 4. The 3D AFM image of the $\alpha-\mathrm{Fe}_{2} \mathrm{O}_{3}$ nanoparticle-modified electrode clearly shows the presence of nanoparticles on the surface of the electrode (Figure 4(a)). The 2D AFM image further confirms the presence of 30-50 nm $\alpha-\mathrm{Fe}_{2} \mathrm{O}_{3}$ nanoparticles, and aggregated spherical particles are found on the surface (Figure 4(b)).

The EDX spectra and elemental mapping for the prepared $\alpha-\mathrm{Fe}_{2} \mathrm{O}_{3}$ nanoparticles were recorded and are shown in Figure 5. The EDX elemental mapping from the FESEM analysis clearly confirms the presence of Fe and $\mathrm{O}$ in the $\alpha$ $\mathrm{Fe}_{2} \mathrm{O}_{3}$ nanoparticles, along with $\mathrm{Si}$ as a result of the $\mathrm{Si}$ wafer. In the EDX spectrum, peaks are observed at $0.5,6.4$, and 7.1 for Fe, 0.2 and 0.4 for O, and 1.7 for Si because of the Si wafer. The absence of other elements indicates that the prepared nanoparticles have a high purity level.

3.4. Electrochemical Behavior of $\alpha-\mathrm{Fe}_{2} \mathrm{O}_{3}$ NanoparticleModified Electrode. Cyclic voltammograms were recorded for thebare $\mathrm{GC}$ and $\alpha-\mathrm{Fe}_{2} \mathrm{O}_{3}$ nanoparticle-modified electrode in $0.1 \mathrm{M} \mathrm{KCl}$ at a scan rate of $50 \mathrm{mVs}^{-1}$ and are shown in Figure 6(a). It can be seen that the $\alpha-\mathrm{Fe}_{2} \mathrm{O}_{3}$ nanoparticlemodified electrode has a higher current than the bare GCE, which is due to the presence of electroactive species $\left(\alpha-\mathrm{Fe}_{2} \mathrm{O}_{3}\right.$ nanoparticles) on the electrode surface. To study 


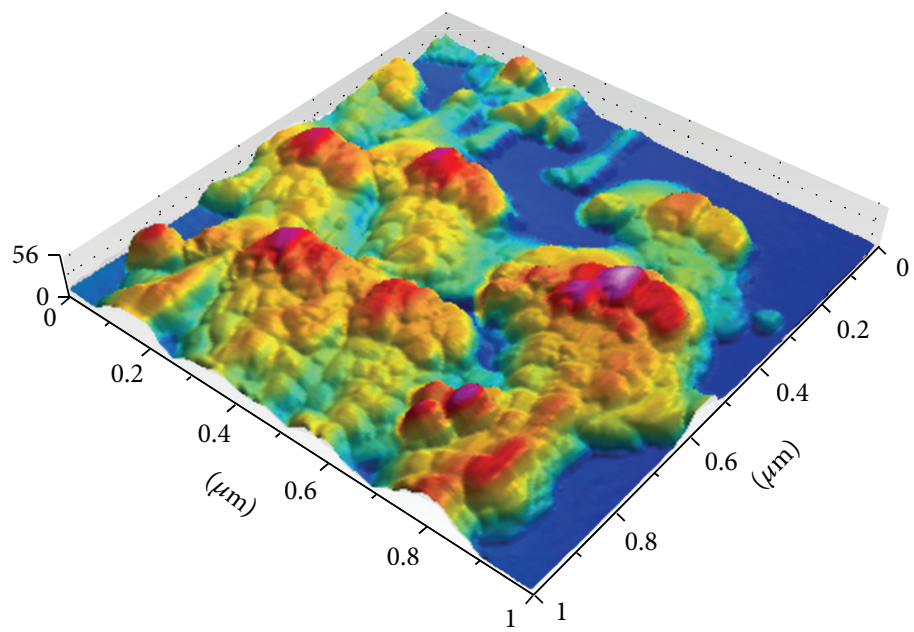

(a)

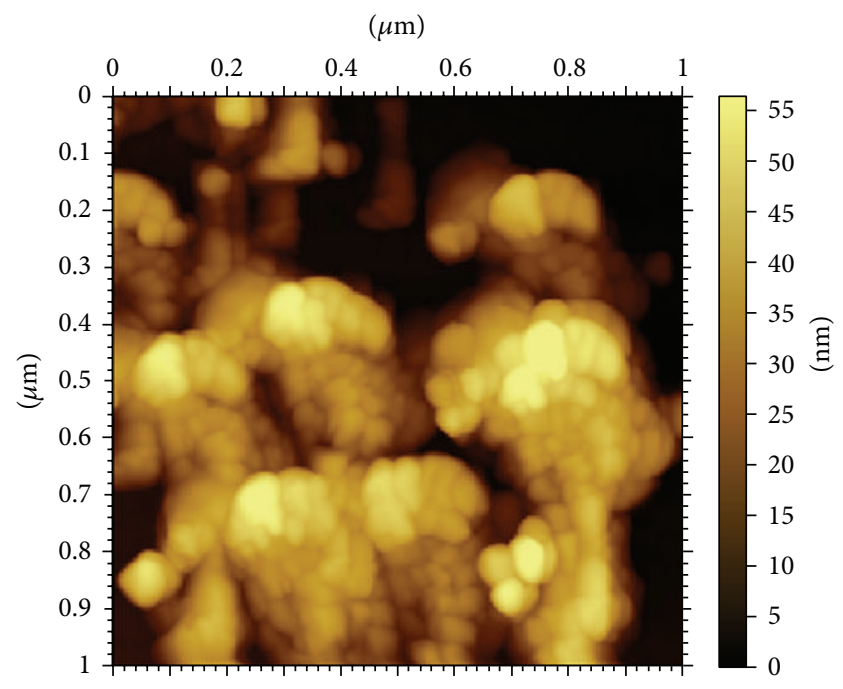

(b)

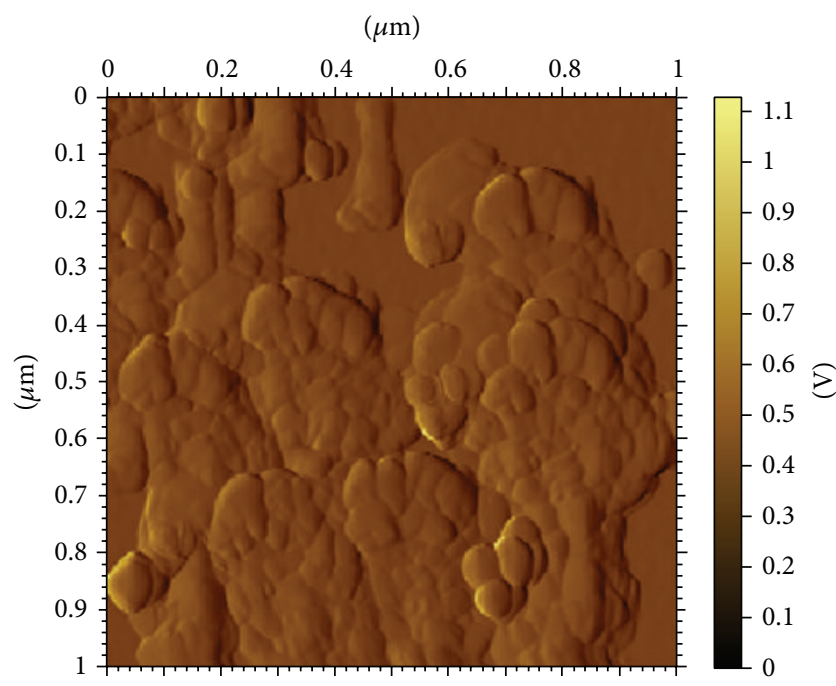

(c)

Figure 4: AFM topography observed for $\alpha-\mathrm{Fe}_{2} \mathrm{O}_{3}$ nanoparticle-modified electrode in (a) angle view (3D), (b) top view (2D), and (c) amplitude view images.

the electrochemical behavior of the $\alpha-\mathrm{Fe}_{2} \mathrm{O}_{3}$ nanoparticlemodified electrode, an $\left[\mathrm{Fe}(\mathrm{CN})_{6}\right]^{3-/ 4-}$ redox couple was used as an electrochemical probe. The cyclic voltammogram recorded for the $\left[\mathrm{Fe}(\mathrm{CN})_{6}\right]^{3-/ 4-}$ couple at the bare GC electrode in a $0.1 \mathrm{M} \mathrm{KCl}$ solution showed a reversible electrochemical response for the $[\mathrm{Fe}(\mathrm{CN}) 6]^{3-/ 4-}$ couple (Figure 6(b)(a)). After the modification of the GC electrode with $\alpha-\mathrm{Fe}_{2} \mathrm{O}_{3}$ nanoparticles, an increase in the peak currents and decrease in the peak potential separation $\left(\Delta E_{p}\right)$ were observed for the $\left[\mathrm{Fe}(\mathrm{CN})_{6}\right]^{3-/ 4-}$ couple (Figure 6(b)(b)) compared to those of the bare GC electrode. On the other hand, $\alpha-\mathrm{Fe}_{2} \mathrm{O}_{3}$ nanoparticles can act as an electron transfer medium and enhance electron transfer during an electrochemical reaction. The introduction of $\alpha-\mathrm{Fe}_{2} \mathrm{O}_{3}$ nanoparticles on the GC electrode surface facilitates the conduction pathway at the modified electrode surface.
The electroactive surface area $(A)$ of an electrode can be easily calculated from the slope obtained by the RandlesSevcik plot described by the following:

$$
i_{p}=2.69 \times 10^{5} n^{3 / 2} v^{1 / 2} D^{1 / 2} A C
$$

where $n, v, D, A$, and $C$ are the number of electrons, scan rate, diffusion coefficient $\left(\mathrm{cm}^{2} \mathrm{~s}^{-1}\right)$, surface area of the electrode, and concentration (in $\mathrm{mol} \cdot \mathrm{L}^{-1}$ ), respectively [14]. The diffusion coefficient $(D)$ can be estimated using the Cottrell equation as follows:

$$
I=\frac{n F A D^{1 / 2} C}{\pi^{1 / 2} t^{1 / 2}}
$$

where $C, A, F$, and $n$ are the bulk concentration $\left(\mathrm{mol} \mathrm{cm}^{-3}\right)$, area of the electrode $\left(\mathrm{cm}^{2}\right)$, Faraday constant 


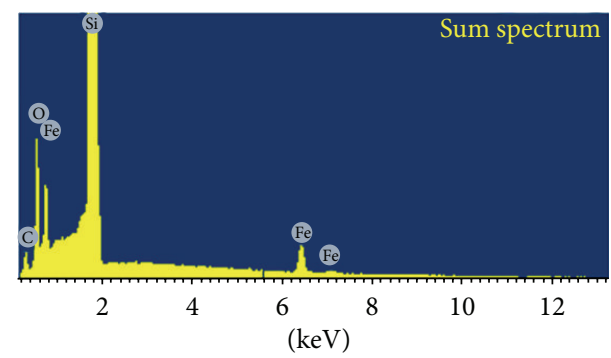

(a)

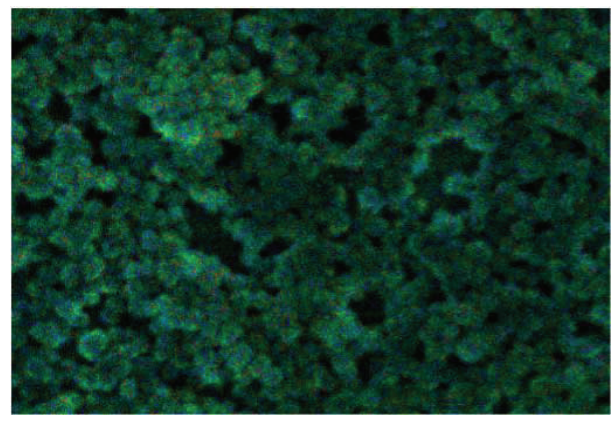

(b)

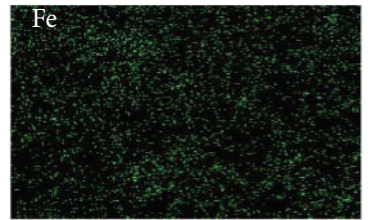

(c)

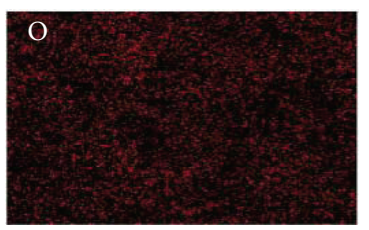

(d)

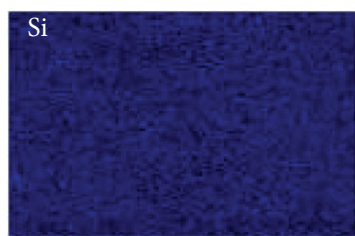

(e)

FIGURE 5: (a) EDX analysis and (b) FESEM-EDX elemental mapping of $\alpha-\mathrm{Fe}_{2} \mathrm{O}_{3}$ nanoparticles on Si wafer for different elements: (c) Fe, (d) $\mathrm{O}$, and (e) Si.

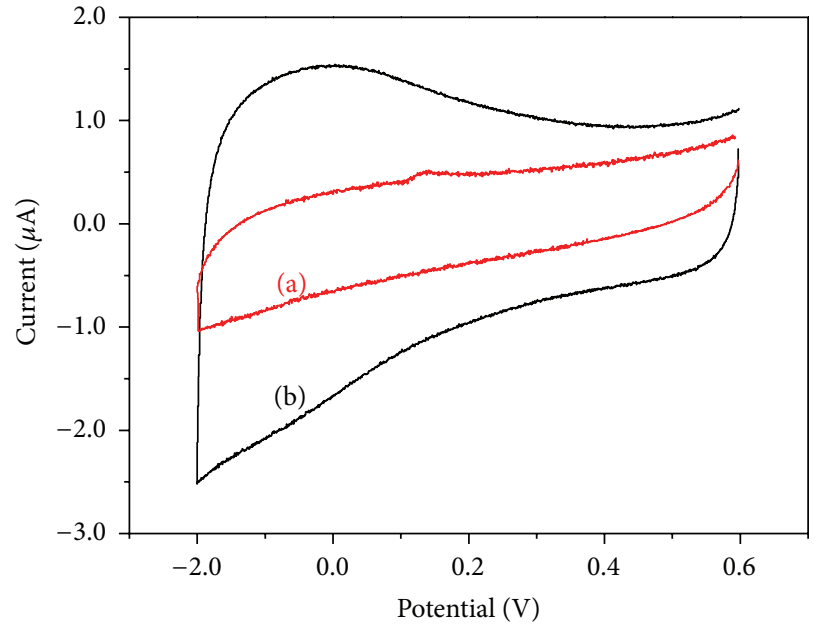

(a)

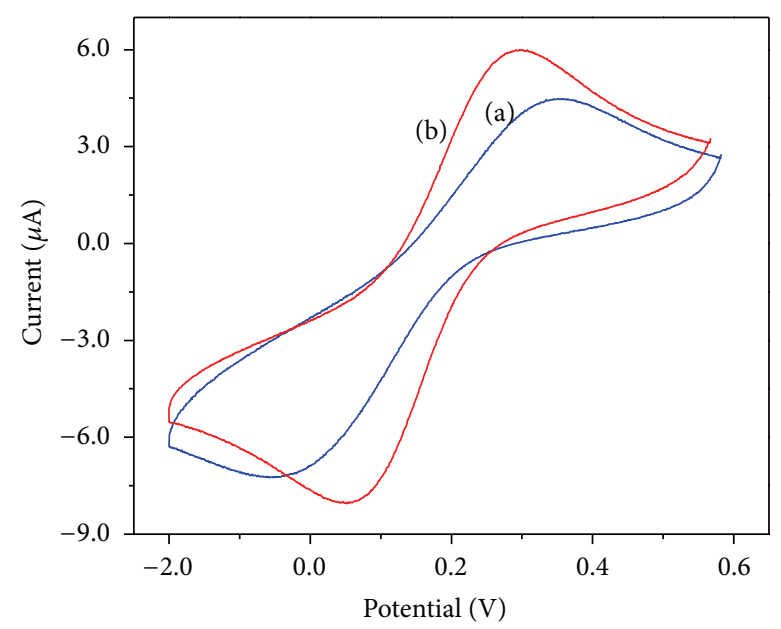

(b)

FIGURE 6: Cyclic voltammograms recorded for (a) bare GC and (b) $\alpha-\mathrm{Fe}_{2} \mathrm{O}_{3}$ nanoparticle-modified electrode with $0.1 \mathrm{M} \mathrm{KCl}$ in (a) absence and (b) presence of $1 \times 10^{-3} \mathrm{M} \mathrm{K}_{3}\left[\mathrm{Fe}(\mathrm{CN})_{6}\right]$ at scan rate of $50 \mathrm{mVs}^{-1}$.

$\left(96,485 \mathrm{Cmol}^{-1}\right)$, and number of electrons $(n=1$ for $\left.\left[\mathrm{Fe}(\mathrm{CN})_{6}\right]^{3-/ 4-}\right)$. By relating the amount of electroactive sites for each electrode in the $[\mathrm{Fe}(\mathrm{CN}) 6]^{3-/ 4-}$ solution that effectively transfers the charge to the species in solution, the electroactive surface area can be obtained. The surface areas for the modified electrode and bare GC were calculated to be $11.5 \mathrm{~mm}^{2}$ and $7.068 \mathrm{~mm}^{2}$, respectively, which show a $62.7 \%$ increase in the surface area of the modified electrode. An increase in the peak current resulted from increasing the electroactive surface area, as observed in the hematitemodified electrode [15]. The peak-to-peak separation $(\Delta E)$ of the $\mathrm{CV}$ results can be used to investigate the reversibility of the electrochemical process in the electrodes. The peak separation for a reversible process can be calculated as follows:

$$
\Delta E_{p}=E_{\mathrm{pa}}-E_{\mathrm{pc}}=\frac{0.059}{n}
$$




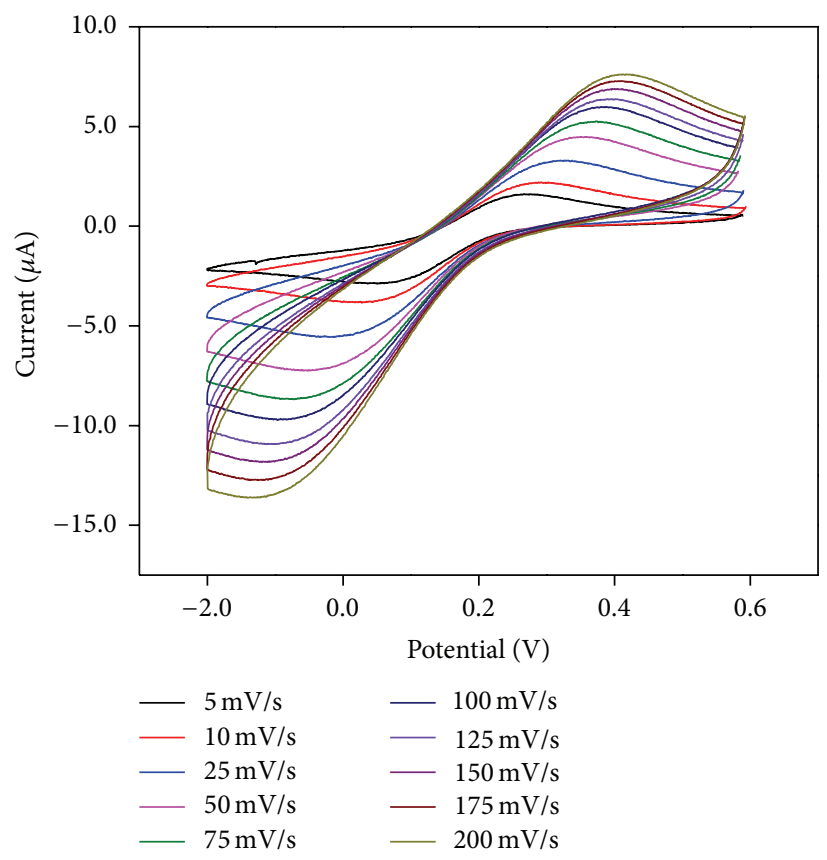

(a)

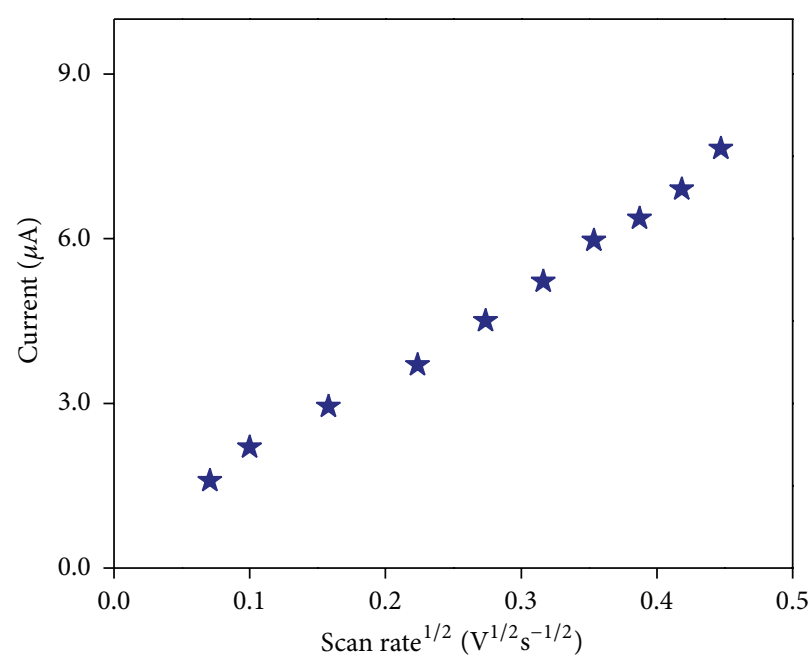

(c)

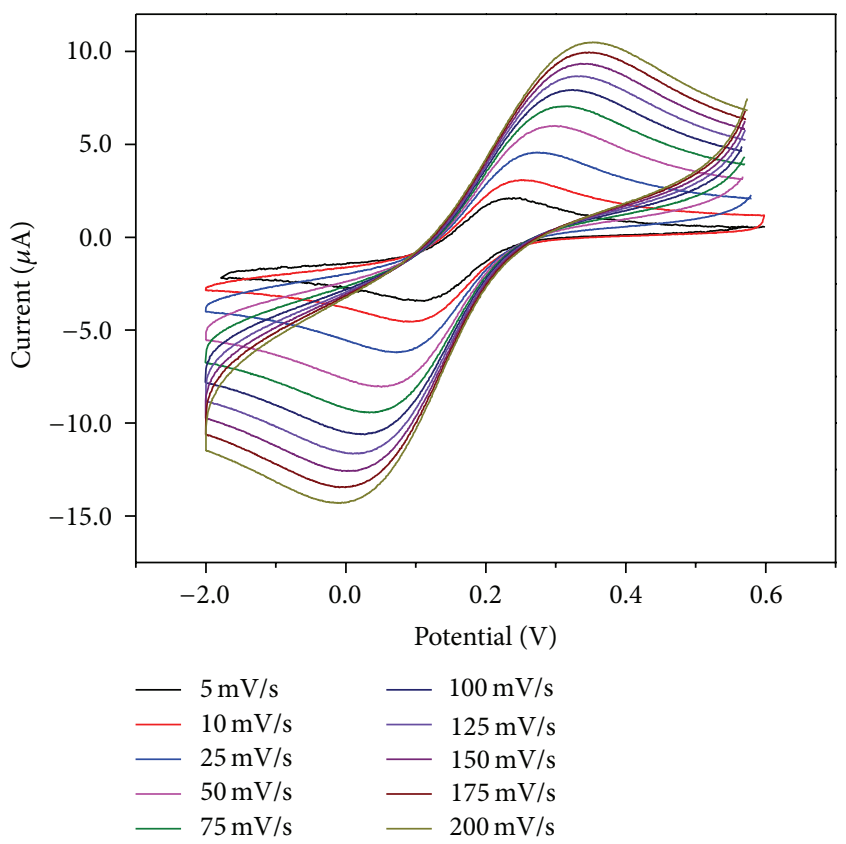

(b)

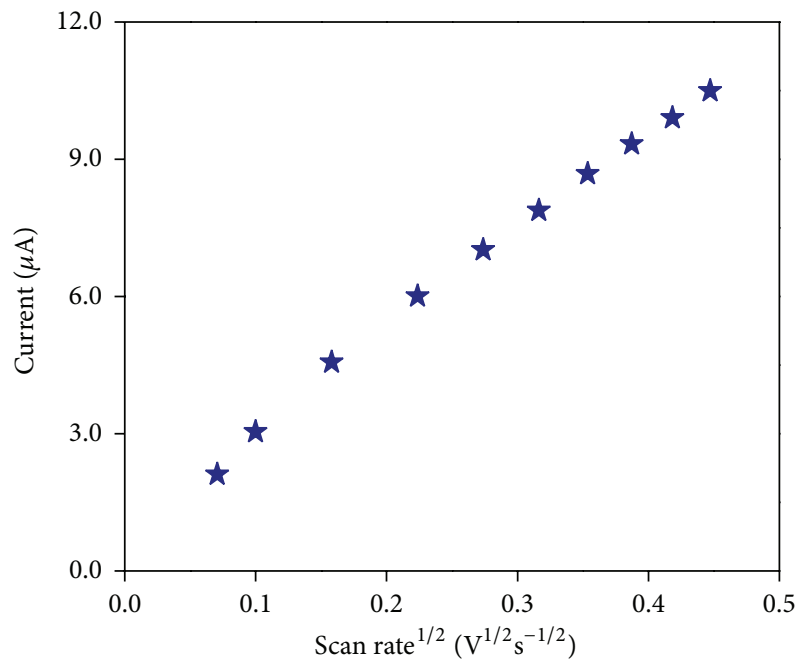

(d)

Figure 7: Cyclic voltammograms recorded at (a) bare GC and (b) $\alpha-\mathrm{Fe}_{2} \mathrm{O}_{3}$ nanoparticle-modified electrode for $1 \times 10^{-3} \mathrm{M}$ of $\mathrm{K}_{3}\left[\mathrm{Fe}(\mathrm{CN})_{6}\right]$ in $0.1 \mathrm{M} \mathrm{KCl}$ at different scan rates: $5-200 \mathrm{mVs}^{-1}$. The plots of the anodic peak current versus scan rate ${ }^{1 / 2}$ obtained for the (c) bare GC and (d) $\alpha-\mathrm{Fe}_{2} \mathrm{O}_{3}$ nanoparticle-modified electrodes.

where $\Delta E_{p}$ is the minimum theoretical peak-to-peak separation, $E_{\mathrm{pa}}$ is the anodic peak potential, and $E_{\mathrm{pc}}$ is the cathodic peak potential. In a reversible reaction process, $\Delta E$ is greater than $\Delta E_{p}$, whereas in an irreversible reaction process, only one peak will be observed in one of the potential scans [14]. The $\Delta E$ values for the bare GCE and GC/ $\alpha-\mathrm{Fe}_{2} \mathrm{O}_{3}$-modified electrode were 291 and $237 \mathrm{mV}$, respectively, which are greater than the $\Delta E_{p}$ of $59 \mathrm{mV}$, indicating that the electrochemical redox reaction in both electrodes is quasireversible. The scan rate was varied in the range of $5-200 \mathrm{mVs}^{-1}$ for the bare GC and $\mathrm{GC} / \alpha-\mathrm{Fe}_{2} \mathrm{O}_{3}$ electrodes with $1 \times 10^{-3} \mathrm{M}$ of $\mathrm{K}_{3}\left[\mathrm{Fe}(\mathrm{CN})_{6}\right]$ in $0.1 \mathrm{M} \mathrm{KCl}$, and the results are shown in Figure 7.

In order to investigate the electrical conductivities of the bare GC and $\alpha-\mathrm{Fe}_{2} \mathrm{O}_{3}$ nanoparticle-modified electrode, electrochemical impedance spectroscopic (EIS) analyses were performed by dipping the bare GC and $\mathrm{GC} / \alpha-\mathrm{Fe}_{2} \mathrm{O}_{3}$ electrode into a solution containing $1 \times 10^{-3} \mathrm{M} \mathrm{K}_{3}\left[\mathrm{Fe}(\mathrm{CN})_{6}\right]$ in $0.1 \mathrm{M} \mathrm{KCl}$ and using scanning frequencies ranging between 0.01 and $100,000 \mathrm{~Hz}$. The observed EIS results for the bare GC and $\mathrm{GC} / \alpha-\mathrm{Fe}_{2} \mathrm{O}_{3}$ electrode are shown in Figure 8. 
The observed diameter of the semicircle is equal to the charge transfer kinetics of the redox probe at the electrode interface, where $Z_{\text {re }}$ and $Z_{\text {im }}$ are real and imaginary parts of the impedance spectra $(Z)$. The bare GC electrode shows a semicircle with a larger diameter. Interestingly, the GC electrode modified with $\alpha-\mathrm{Fe}_{2} \mathrm{O}_{3}$ nanoparticles showed a significant decrease in the semicircle diameter of the Nyquist plot. This indicated that the charge transfer resistance decreased upon the modification of the $\alpha-\mathrm{Fe}_{2} \mathrm{O}_{3}$ nanoparticles. The charge transfer resistance $\left(R_{\mathrm{ct}}\right)$ values for both the bare GC and the $\alpha-\mathrm{Fe}_{2} \mathrm{O}_{3}$ nanoparticle-modified electrode were calculated by applying the following equation [16]:

$$
R_{\mathrm{ct}}=\frac{R T}{n F i_{0}},
$$

where $R_{\mathrm{ct}}$ is the charge transfer resistance due to the transferring of electrons at the electrode/electrolyte solution interface, $R$ is a gas constant, $T$ is the experimental temperature, $n$ is the electron transfer number of the redox process, which could be considered to be equal to one for $\left[\mathrm{Fe}(\mathrm{CN})_{6}\right]^{4-} /\left[\mathrm{Fe}(\mathrm{CN})_{6}\right]^{3-}$ couple, $F$ is the Faraday constant, and $i_{0}$ is the exchange current of the redox probe [16]. The bare GC and $\alpha-\mathrm{Fe}_{2} \mathrm{O}_{3}$ nanoparticle-modified electrode had $R_{\mathrm{ct}}$ values of 180 and $25 \mathrm{k} \Omega$, respectively. It should be noted that the $R_{\mathrm{ct}}$ value of the $\alpha-\mathrm{Fe}_{2} \mathrm{O}_{3}$ nanoparticle-modified electrode is lower than that of the bare GC electrode, which is mainly attributed to the high electron conductivity of the $\alpha$ $\mathrm{Fe}_{2} \mathrm{O}_{3}$ nanoparticle-modified electrode and the sluggish electron transfer behavior of the bare GC. This clearly shows that the $\alpha-\mathrm{Fe}_{2} \mathrm{O}_{3}$ nanoparticle-modified electrode is a promising candidate for electrocatalysis and sensor applications.

\subsection{Electrocatalytic Activity of $\alpha-\mathrm{Fe}_{2} \mathrm{O}_{3}$ Nanoparticle-Modified} Electrode toward Dopamine. Cyclic voltammograms were recorded from the bare $\mathrm{GC}$ and $\mathrm{GC} / \alpha-\mathrm{Fe}_{2} \mathrm{O}_{3}$-modified electrode for $50 \mu \mathrm{M}$ of DA in a $0.1 \mathrm{M}$ PBS solution $(\mathrm{pH}=6.8)$ at a scan rate of $50 \mathrm{mVs}^{-1}$ and are shown in Figure 9. It can be observed that the bare GCE has quasireversible, poorly defined redox peaks and a low electrochemical response toward DA. However, a significant increase in the redox peak current was detected for the $\mathrm{GC} / \alpha-\mathrm{Fe}_{2} \mathrm{O}_{3}$-modified electrode, contributing to its improved conductivity performance. Hence, the $\mathrm{GC} / \alpha-\mathrm{Fe}_{2} \mathrm{O}_{3}$-modified electrode exhibited reversible behavior and possessed faster electron transfer kinetics, as reflected in its low $\Delta E_{p}$ value.

The effect of the scan rate on the DA oxidation was studied for the bare $\mathrm{GC}$ and $\mathrm{GC} / \alpha-\mathrm{Fe}_{2} \mathrm{O}_{3}$-modified electrode by varying the scan rate from 5 to $200 \mathrm{mVs}^{-1}$ with $50 \mu \mathrm{M}$ of DA in a $0.1 \mathrm{M}$ PBS ( $\mathrm{pH}=6.8$ ) (Figure 10). At the $200 \mathrm{mVs}^{-1}$ scan rate, we observed a redox peak with an anodic-to-cathodic ratio of 1.37, which was slightly higher than the unit value expected for the ideal voltammetric behavior of a GC/ $\alpha-\mathrm{Fe}_{2} \mathrm{O}_{3}$-modified electrode for reversibility. The peak separations $(\Delta E)$ of the bare electrode and $\mathrm{GC} / \alpha-\mathrm{Fe}_{2} \mathrm{O}_{3}$-modified electrode for all the scan rates in the range of $5-200 \mathrm{mVs}^{-1}$ were greater than $295 \mathrm{mV}$ (due to the two electron transfers), which indicated a reversible redox process. Increasing the scan rate increased the peak separation $(\Delta E)$ because of the chemical interaction

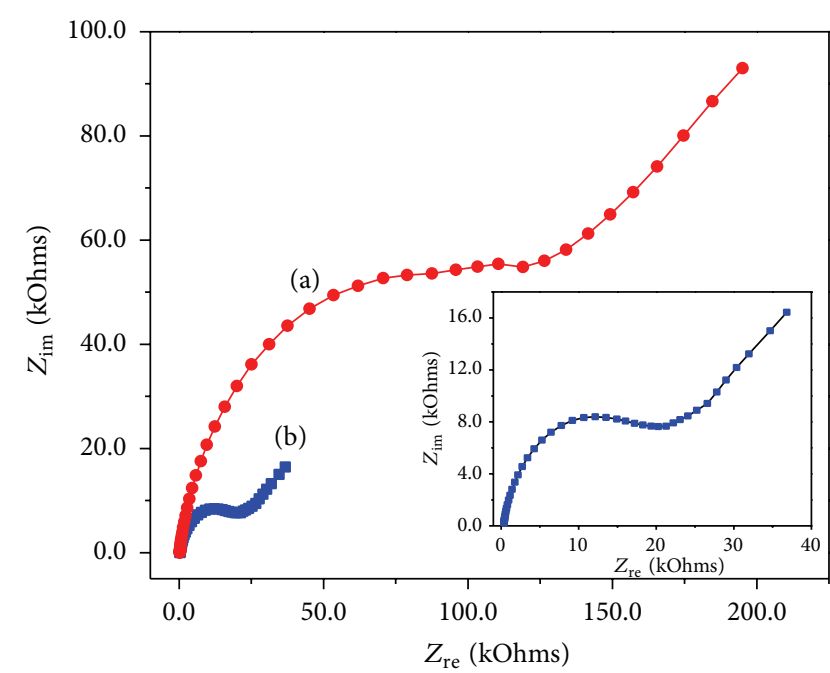

FIGURE 8: Electrochemical impedance spectra (EIS) obtained for (a) bare GC and (b) $\alpha-\mathrm{Fe}_{2} \mathrm{O}_{3}$ nanoparticle-modified electrode in $1 \times$ $10^{-3} \mathrm{M} \mathrm{K}_{3}\left[\mathrm{Fe}(\mathrm{CN})_{6}\right]$ in $0.1 \mathrm{M} \mathrm{KCl}$. (Inset) Expanded view of EIS of $\alpha-\mathrm{Fe}_{2} \mathrm{O}_{3}$ nanoparticle-modified electrode.

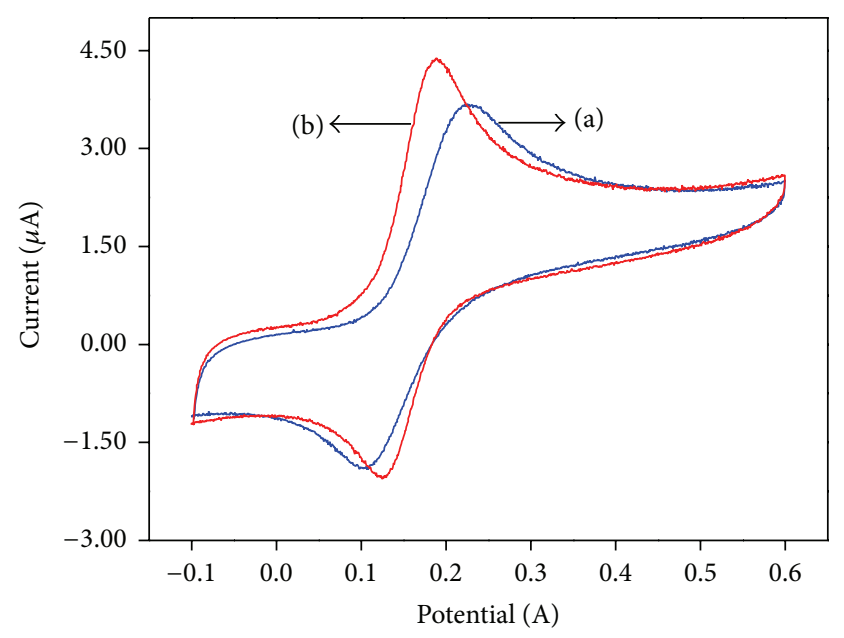

FIGURE 9: Cyclic voltammograms recorded at (a) bare GC and (b) $\alpha$ - $\mathrm{Fe}_{2} \mathrm{O}_{3}$-modified electrode for $50 \mu \mathrm{M}$ of DA in $0.1 \mathrm{M}$ PBS solution $(\mathrm{pH}=6.8)$ at scan rate of $50 \mathrm{mVs}^{-1}$.

between the DA and the modified electrode. Simultaneous increases in the anodic and cathodic current intensities were also observed when increasing the scan rate. A plot of the anodic and cathodic current $\left(I_{\mathrm{pa}}\right)$ peaks versus the square root of the scan rate is shown in Figure 10. It shows the linear relation for the $\mathrm{GC} / \alpha-\mathrm{Fe}_{2} \mathrm{O}_{3}$-modified electrode $\left(R^{2}=\right.$ 0.9943 and 0.9931 ), which indicates a diffusion controlled redox process $[3,17-20]$.

3.6. Influence of $\mathrm{pH}$ on Electrocatalytic Activity of $\alpha-\mathrm{Fe}_{2} \mathrm{O}_{3}$ Nanoparticle-Modified Electrode. The influence of the electrolyte solution $\mathrm{pH}$ on the electrochemical reaction to the $\mathrm{DA}$ in the presence of the $\alpha-\mathrm{Fe}_{2} \mathrm{O}_{3}$ nanoparticle-modified electrodewas studied in phosphate buffer solutions with 


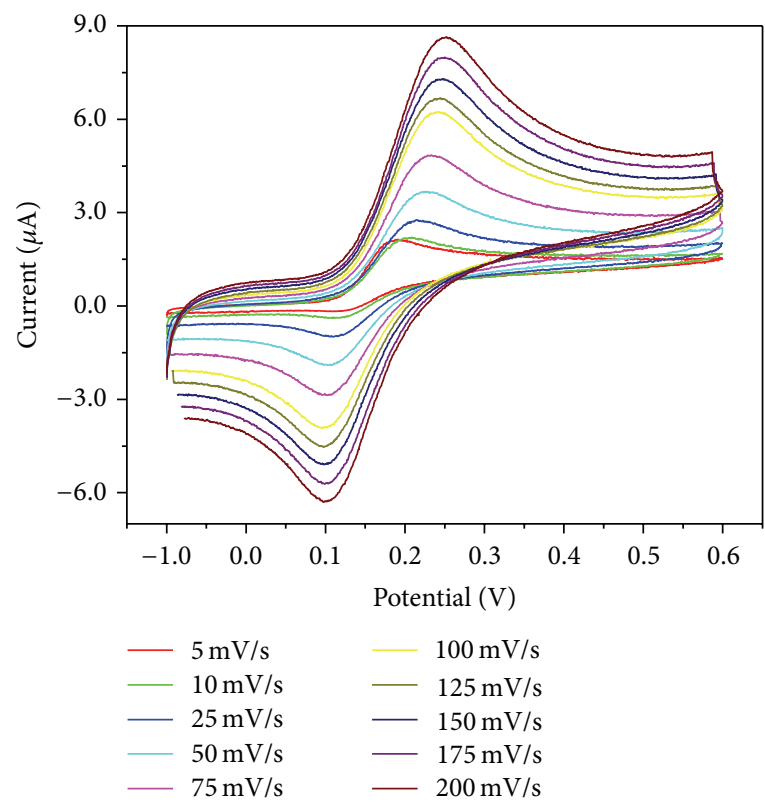

(a)

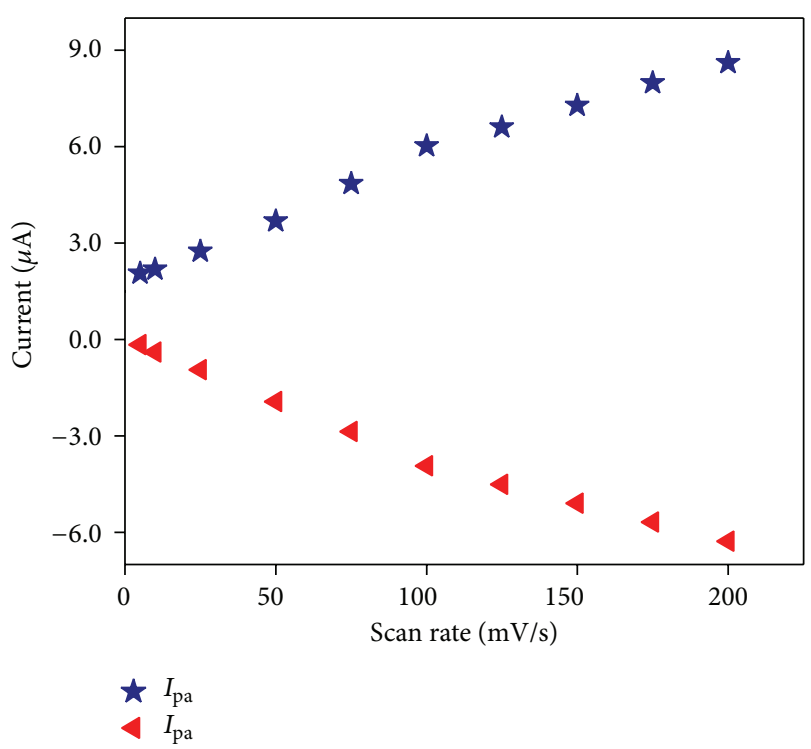

(c)

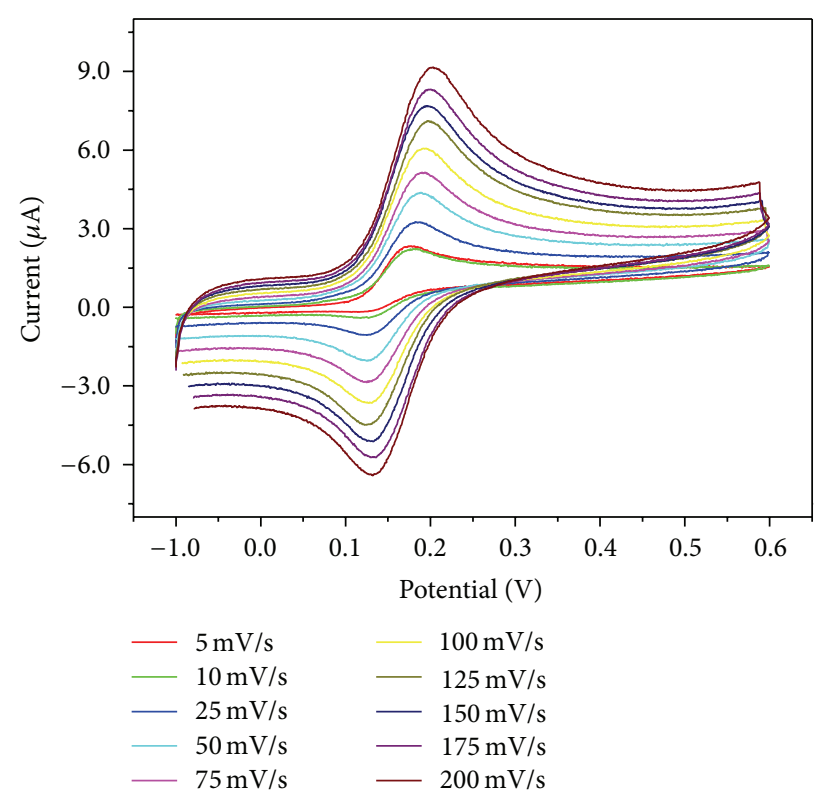

(b)

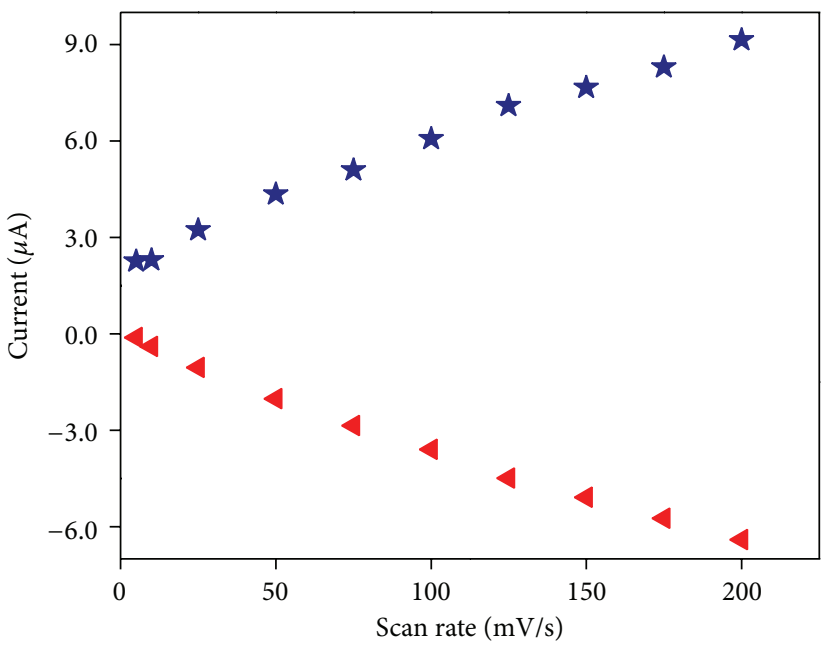

(d)

FIGURE 10: Cyclic voltammograms recorded for (a) bare GC and (b) $\alpha-\mathrm{Fe}_{2} \mathrm{O}_{3}$ nanoparticle-modified electrode with $50 \mu \mathrm{M}$ of DA in $0.1 \mathrm{M}$ PBS $(\mathrm{pH}=6.8)$ at different scan rates: $5-200 \mathrm{mVs}^{-1}$. The plots of the peak current versus scan rate $\mathrm{f}^{1 / 2}$ obtained for the (c) bare GC and (d) $\alpha-\mathrm{Fe}_{2} \mathrm{O}_{3}$ nanoparticle-modified electrode.

various $\mathrm{pH}$ values ranging from 3 to 11 , and the observed cyclic voltammograms are shown in Figure 11(a). It can be observed that increasing the $\mathrm{pH}$ of the electrolyte solution leads to negative shifts in both the anodic and the cathodic peak potentials, which suggests that the redox reaction of DA includes some protons transfers at the modified electrode. In addition, the influence of the $\mathrm{pH}$ on the anodic peak potential of DA was also studied, and the obtained results are shown in Figure 11(b). From Figure 11(c), it can be noted that the applied potential $\left(E_{\mathrm{pa}}\right)$ versus the $\mathrm{pH}$ shows a linear relationship in the $\mathrm{pH}$ range of 3 to 11, with a slope value of
$-75.05 \mathrm{mV} / \mathrm{pH}$ and this observed slope value is higher than the theoretical value of $-59 \mathrm{mV} / \mathrm{pH}$.

3.7. Chronoamperometric Detection of Dopamine. The chronoamperometric technique was also used to determine the applicability of the $\mathrm{GC} / \alpha-\mathrm{Fe}_{2} \mathrm{O}_{3}$-modified electrode for DA sensing. Figure 12 shows the chronoamperometric response of the GCE $/ \alpha-\mathrm{Fe}_{2} \mathrm{O}_{3}$-modified electrode upon the stepwise addition of $500 \mathrm{nM}$ into the $0.1 \mathrm{M}$ PBS $(\mathrm{pH}=6.8)$ at an applied potential of $200 \mathrm{mV}$. Figure 12 shows the increase in the current with increasing DA concentration in the range 


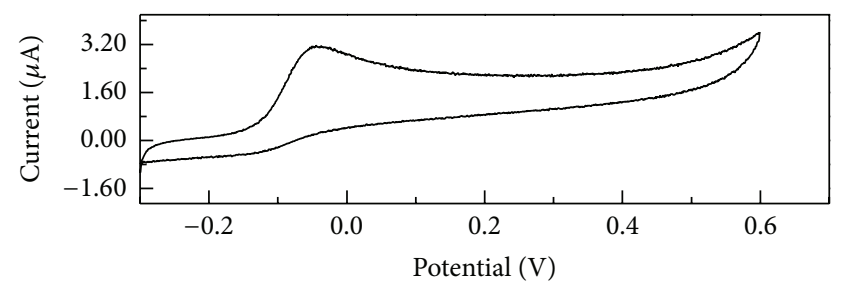

$-\mathrm{pH} 11$

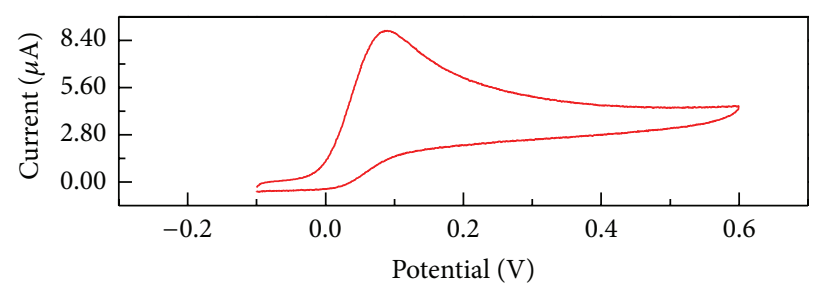

$-\mathrm{pH} 9$

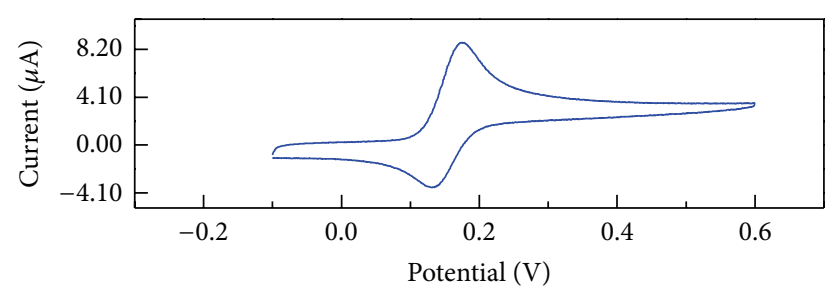

$-\mathrm{pH} 7$

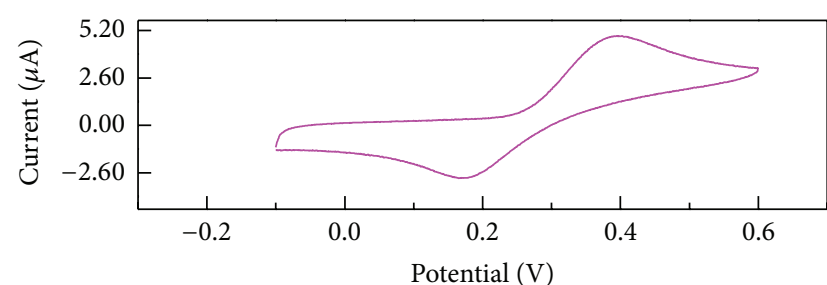

$-\mathrm{pH} 5$

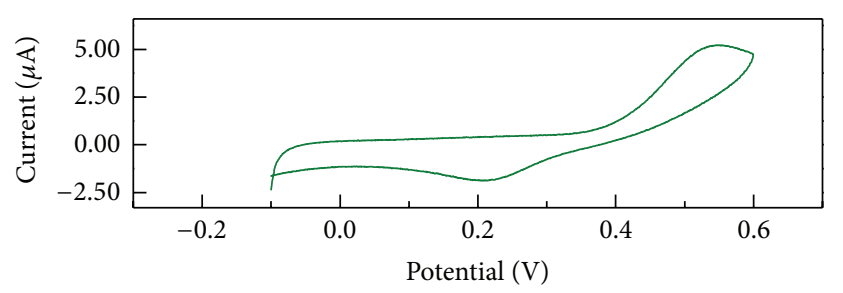

$-\mathrm{pH} 3$

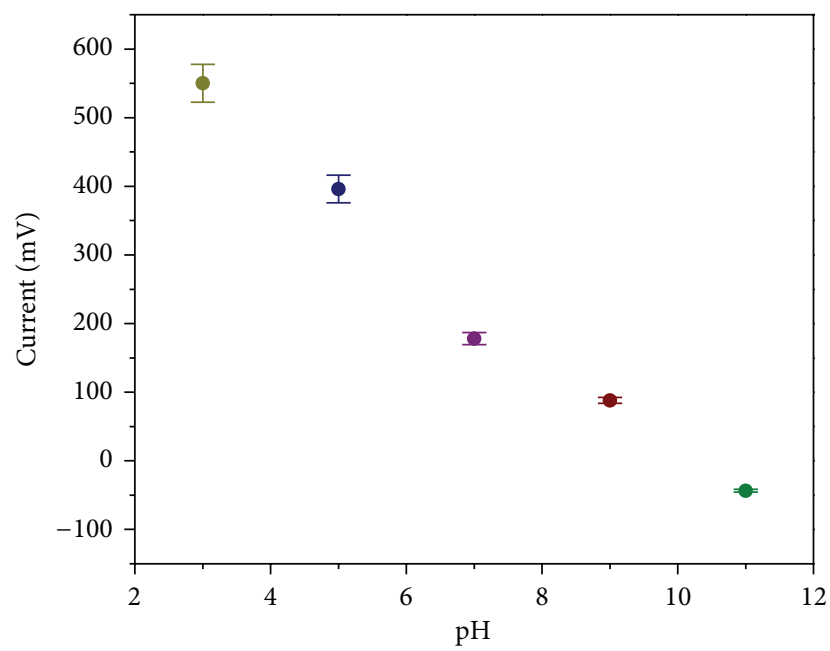

(b)

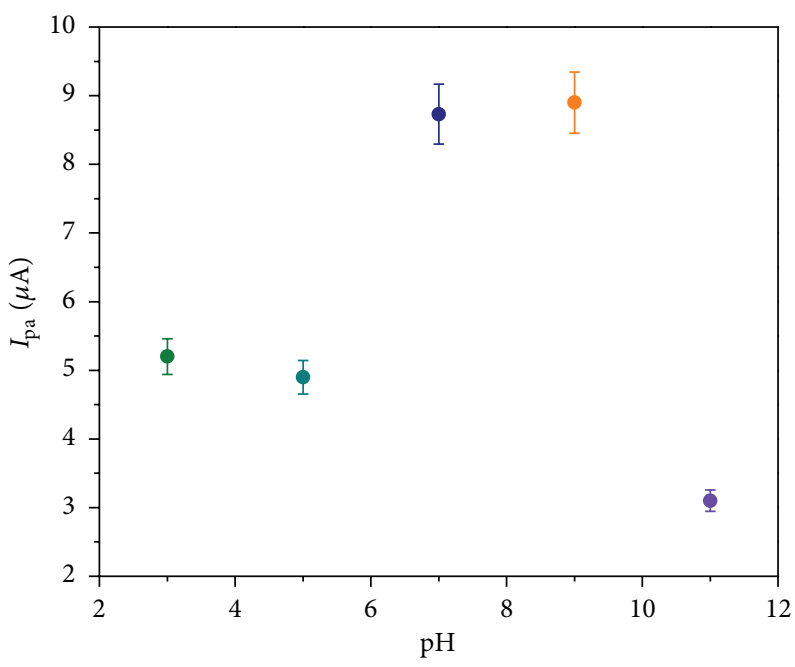

(c)

Figure 11: (a) Cyclic voltammograms recorded at $\alpha$ - $\mathrm{Fe}_{2} \mathrm{O}_{3}$ nanoparticle-modified electrode for $50 \mu \mathrm{M}$ of DA in $0.1 \mathrm{M}$ PBS with different pH values at scan rate of $50 \mathrm{mVs}^{-1}$. Plots of (b) anodic peak potential $\left(E_{\mathrm{pa}}\right)$ and (c) anodic peak current $\left(I_{\mathrm{pa}}\right)$ against different pH values for PBS solution.

of 0.5 to $5 \mu \mathrm{M}$. From the calibration plot (Figure 12(b)), it is observed that increasing the DA concentration leads to slow saturation of the current response due to the saturation of the catalytic sites of the modified electrode at a high concentration of DA.

The linear relation of the dopamine concentration and the current in the range of 0 to $2 \mu \mathrm{M}$ can be calculated from a calibration plot with a correlation coefficient $(R)$ of $0.9845(n=10)$ for the following regression equation [21]: $I(\mu \mathrm{A})=0.8867+1.6546(\mu \mathrm{M})$. The limit of detection (LoD) was calculated to be $1.6 \mu \mathrm{M}$ (signal-to-noise ratio $(S / N)=$ $3)$ by substituting the blank standard deviation $(\sigma=0.8867)$ and sensitivity $(m=1.6546 \mu \mathrm{A} / \mu \mathrm{M})$ in the $3 \sigma / \mathrm{m}$ criterion [22]. The response time for each DA addition was observed 


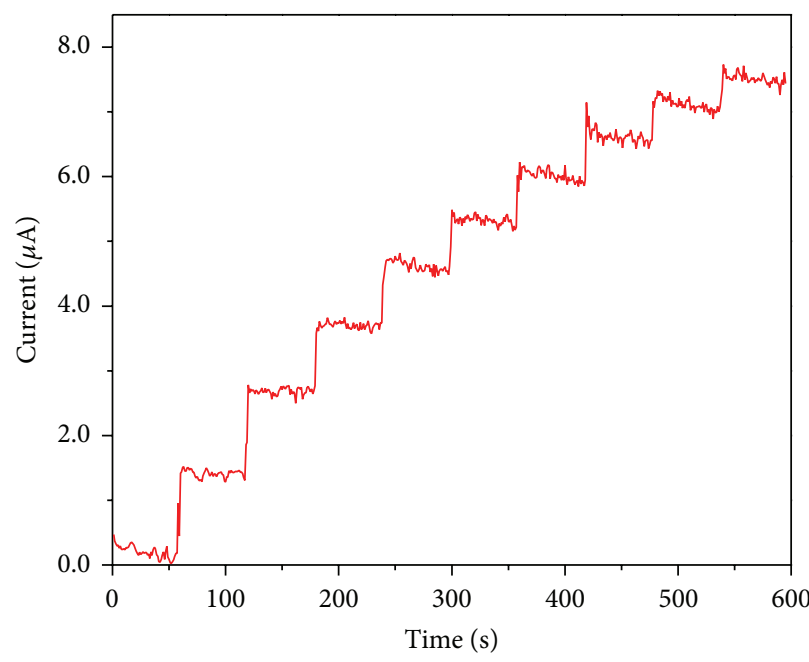

(a)

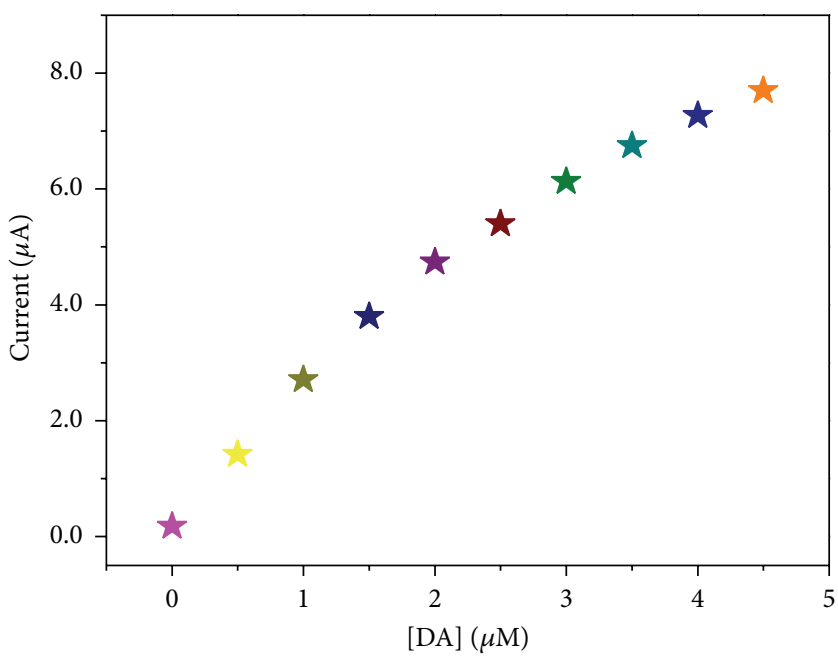

(b)

FIGURE 12: (a) Chronoamperometric I-T curve obtained for $\alpha$ - $\mathrm{Fe}_{2} \mathrm{O}_{3}$ nanoparticle-modified electrode during successive addition of $0.5 \mu \mathrm{M}$ of DA in $0.1 \mathrm{M}$ PBS $(\mathrm{pH}=6.8$ ) at applied potential of $200 \mathrm{mV}$. (b) The calibration curve obtained upon the $0.5 \mu \mathrm{M}$ addition of DA in $0.1 \mathrm{M}$ PBS $(\mathrm{pH}=6.8)$.

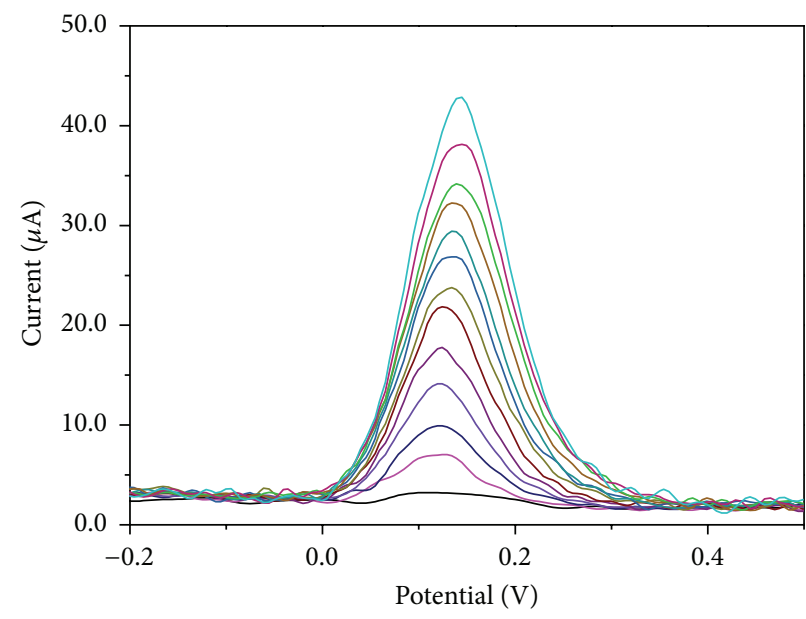

(a)

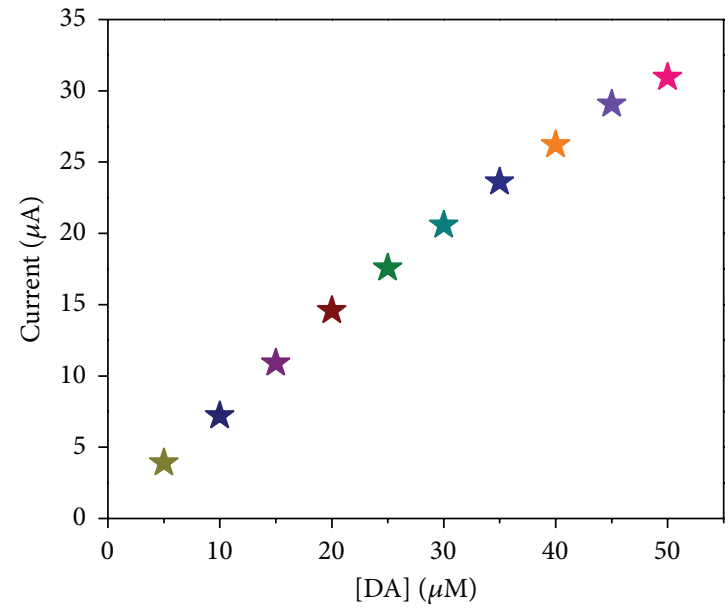

(b)

FIGURE 13: (a) Square wave voltammograms recorded for $\alpha-\mathrm{Fe}_{2} \mathrm{O}_{3}$ nanoparticle-modified electrode during successive addition of $5 \mu \mathrm{M}$ of DA in $0.1 \mathrm{M} \mathrm{PBS}\left(\mathrm{pH}=6.8\right.$ ) at scan rate of $100 \mathrm{mVs}^{-1}$. (b) The calibration curve obtained upon the $5 \mu \mathrm{M}$ addition of DA in $0.1 \mathrm{M}$ PBS (pH = 6.8).

to be $\sim 3 \mathrm{~s}$, which indicates a fast electron transfer with this modified electrode.

3.8. Square Wave Voltammetric Detection of Dopamine. The influence of the dopamine concentration on the electrocatalytic activity was investigated with the $\mathrm{GC} / \alpha-\mathrm{Fe}_{2} \mathrm{O}_{3}$ modified electrode using a square wave voltammetric technique by adding different concentrations of DA into the $0.1 \mathrm{M}$ PBS $(\mathrm{pH}=6.8)$, and the results are shown in Figure 13. It is observed that when the DA concentration increases, the peak current also increases up to $90 \mu \mathrm{M}$ of DA. When the DA concentration was greater than $90 \mu \mathrm{M}$, the modified electrode did not show any further increase in the peak current. This phenomenon is mainly attributed to the saturation of the catalytic sites of the modified electrode. The calibration plot obtained for the modified electrode current response against the dopamine concentration is shown in Figure 13, and it shows a linear relationship toward the DA concentration in the range of 0.0 to $90 \mu \mathrm{M}$. A linear relationship with a correlation coefficient $(R)$ of $0.9974(n=10)$ for the regression equation $I(\mu \mathrm{A})=0.048+1.6827(\mu \mathrm{M})$ was obtained [21]. The LOD was found to be $236 \mathrm{nM}(S / N=3)$ by substituting the blank standard deviation $(\sigma=0.048)$ and sensitivity $(m=$ $0.6099 \mu \mathrm{A} / \mu \mathrm{M})$ in the $3 \sigma / \mathrm{m}$ criterion [22]. 


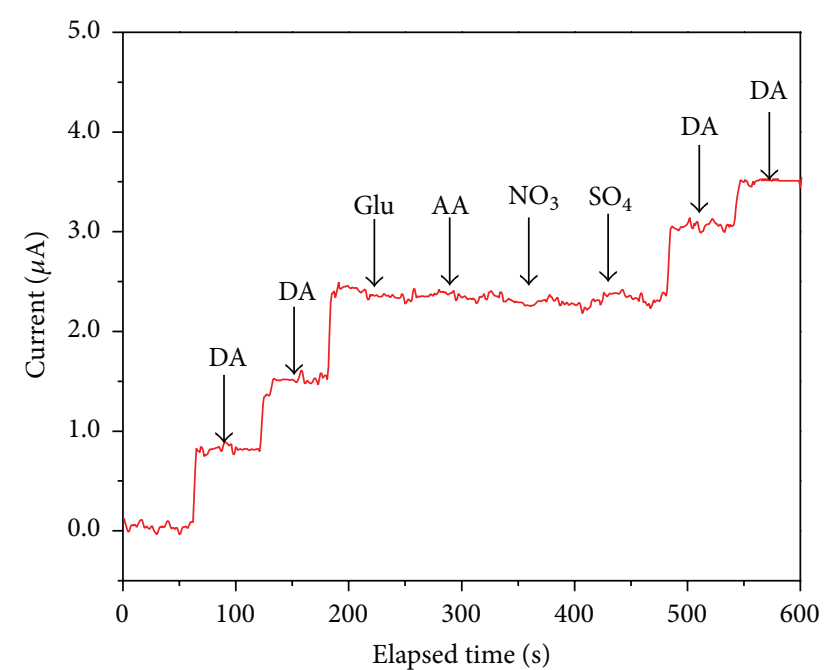

FIGURE 14: Chronoamperometric curve obtained for hematitemodified electrode upon addition of DA and interference sources, including ascorbic acid, glucose, sulphate, and nitrate, at applied potential of $200 \mathrm{mV}$.

3.9. Selectivity Study of $\alpha-\mathrm{Fe}_{2} \mathrm{O}_{3}$ Nanoparticle-Modified Electrode. In order to study the selectivity of the $\alpha-\mathrm{Fe}_{2} \mathrm{O}_{3}$ nanoparticle-modified electrode toward DA, chronoamperometric curves were recorded with common interference sources such as ascorbic acid, glucose, sulphate, and nitrate and are shown in Figure 14. It can be seen that upon the addition of DA, the current is increased, whereas when 100fold higher concentration of an interference source is added, such as $\mathrm{AA}$, Glucose (Glu), $\mathrm{SO}_{4}^{-}$, or $\mathrm{NO}_{2}{ }^{-}$, there is no obvious increase in the current. Further, when DA is added to the same solution, the current increases. This clearly suggests that the fabricated $\alpha-\mathrm{Fe}_{2} \mathrm{O}_{3}$ nanoparticle-modified electrode is more selective toward DA.

\section{Conclusion}

Hematite $\left(\alpha-\mathrm{Fe}_{2} \mathrm{O}_{3}\right)$ nanoparticles were synthesized using a hydrothermal method and characterized by UV-vis, PL, XRD, TEM, AFM, FESEM, and EDX analyses. The experimental results indicated the formation of uniform hematite nanoparticles with an average size of $45 \mathrm{~nm}$. The so-formed $\alpha-\mathrm{Fe}_{2} \mathrm{O}_{3}$ nanoparticles were used to fabricate a sensor electrode for the detection of DA. The electrochemical behavior of this $\mathrm{GC} / \alpha$ $\mathrm{Fe}_{2} \mathrm{O}_{3}$ electrode was studied by using CV and EIS techniques with an electrochemical probe, an $\left[\mathrm{Fe}(\mathrm{CN})_{6}\right]^{3-/ 4-}$ redox couple. The electrocatalytic activity was investigated toward DA oxidation in a phosphate buffer solution ( $\mathrm{pH}$ 6.8) by varying different experimental parameters. The chronoamperometric study showed a linear response in the range of $0-2 \mu \mathrm{M}$ with $\mathrm{LoD}$ of $1.6 \mu \mathrm{M}$ for DA. The square wave voltammetry showed a linear response in the range of $0-35 \mu \mathrm{M}$ with LoD of $236 \mathrm{nM}$ for DA. In a biological system containing a micromolar concentration of DA [23], submicromolar detection would be beneficial using an SWV and CA method for a modified electrode. The results of this study suggested that $\alpha-\mathrm{Fe}_{2} \mathrm{O}_{3}$ nanoparticles could be a promising candidate for the fabrication of ultramicroelectrodes for in vivo DA detection applications.

\section{Conflict of Interests}

The authors declare that there is no conflict of interests regarding the publication of this paper.

\section{Acknowledgments}

The current research work was supported by the University of Malaya research Grant UMRG Program (RP007C13AFR), Program Rakan Penyelidikan Universiti Malaya (PRPUM, CG0002-2013), and a High Impact Research Grant from the Ministry of Higher Education of Malaysia (UM.C/625/1/HIR/MOHE/05).

\section{References}

[1] T. Wang, C. Zhang, J. Lian, Y. Liang, W. Yuan, and S. Zhou, "Facile synthesis of hematite nanoparticles and nanocubes and their shape-dependent optical properties," New Journal of Chemistry, vol. 38, pp. 46-49, 2014.

[2] N. D. Cuong, D. Q. Khieu, N. D. Hoa, N. van Hieu, and T. T. Hoa, "Gas sensor based on nanoporous hematite nanoparticles: effect of synthesis pathways on morphology and gas sensing properties," Current Applied Physics, vol. 12, no. 5, pp. 1355-1360, 2012.

[3] H. Liu, Y. Wei, P. Li, Y. Zhang, and Y. Sun, "Catalytic synthesis of nanosized hematite particles in solution," Materials Chemistry and Physics, vol. 102, no. 1, pp. 1-6, 2007.

[4] M. Zhu, Y. Wang, D. Meng, X. Qin, and G. Diao, "Hydrothermal synthesis of hematite nanoparticles and their electrochemical properties," The Journal of Physical Chemistry C, vol. 116, no. 30, pp. 16276-16285, 2012.

[5] Z. Liu, B. Lv, Y. Xu, and D. Wu, "Hexagonal $\alpha-\mathrm{Fe}_{2} \mathrm{O}_{3}$ nanorods bound by high-index facets as high-performance electrochemical sensor," Journal of Materials Chemistry A, vol. 1, no. 9, pp. 3040-3046, 2013.

[6] G. S. H. Thien, A. Pandikumar, N. M. Huang, and H. N. Lim, "Highly exposed 001 facets of titanium dioxide modified with reduced graphene oxide for dopamine sensing," Scientific Reports, vol. 4, p. 5044, 2014.

[7] W. Cai, H. Du, J. Ye, and T. Lai, "Electrochemical determination of ascorbic acid, dopamine and uricacid based on an exfoliated graphite paper electrode: a high performance flexible sensor," Sensors and Actuators B: Chemical, vol. 193, pp. 492-500, 2014.

[8] R. M. Cornell and U. Schwertmann, The Iron Oxides. Structure, Properties, Reactions, Occurrence and Uses, vol. 24, 2003.

[9] R. Cao, X. Chen, W. Shen, and Z. Long, "A facile route to synthesize nano-hematite colloid," Materials Letters, vol. 65, no. 21-22, pp. 3298-3300, 2011.

[10] Z. Zhang, T. Takahashi, and M. F. Hossain, "Fabrication of shape-controlled $\alpha-\mathrm{Fe}_{2} \mathrm{O}_{3}$ nanostructures by sonoelectrochemical anodization for visible light photocatalytic application," Materials Letters, vol. 64, no. 3, pp. 435-438, 2010. 
[11] R. Dhanalakshmi, A. Pandikumar, K. Sujatha, and P. Gunasekaran, "Photocatalytic and antimicrobial activities of functionalized silicate solgel embedded $\mathrm{ZnO}-\mathrm{TiO}_{2}$ nanocomposite materials," Materials Express, vol. 3, no. 10, pp. 291-300, 2013.

[12] A. Pandikumar, K. Sivaranjani, C. S. Gopinath, and R. Ramaraj, "Aminosilicate sol-gel stabilized $\mathrm{N}$-doped $\mathrm{TiO}_{2}$-Au nanocomposite materials and their potential environmental remediation applications," RSC Advances, vol. 3, no. 32, pp. 13390-13398, 2013.

[13] A. S. Adekunle and K. I. Ozoemena, "Voltammetric and impedimetric properties of nano-scaled $\gamma-\mathrm{Fe}_{2} \mathrm{O}_{3}$ catalysts supported on multi-walled carbon nanotubes: catalytic detection of dopamine," International Journal of Electrochemical Science, vol. 5, no. 12, pp. 1726-1742, 2010.

[14] T. Ndlovu, O. A. Arotiba, S. Sampath, R. W. Krause, and B. B. Mamba, "Reactivities of modified and unmodified exfoliated graphite electrodes in selected redox systems," International Journal of Electrochemical Science, vol. 7, no. 10, pp. 9441-9453, 2012.

[15] L.-H. Han, H. Liu, and Y. Wei, "In situ synthesis of hematite nanoparticles using a low-temperature microemulsion method," Powder Technology, vol. 207, no. 1-3, pp. 42-46, 2011.

[16] A. S. Adekunle, B. O. Agboola, J. Pillay, and K. I. Ozoemena, "Electrocatalytic detection of dopamine at single-walled carbon nanotubes-iron (III) oxide nanoparticles platform," Sensors and Actuators B: Chemical, vol. 148, no. 1, pp. 93-102, 2010.

[17] S. Jo, H. Jeong, S. R. Bae, and S. Jeon, "Modified platinum electrode with phytic acid and single-walled carbon nanotube: application to the selective determination of dopamine in the presence of ascorbic and uric acids," Microchemical Journal, vol. 88, no. 1, pp. 1-6, 2008.

[18] S. Majdi, A. Jabbari, H. Heli, and A. A. Moosavi-Movahedi, "Electrocatalytic oxidation of some amino acids on a nickelcurcumin complex modified glassy carbon electrode," Electrochimica Acta, vol. 52, no. 14, pp. 4622-4629, 2007.

[19] H. Yao, Y. Sun, X. Lin, Y. Tang, and L. Huang, "Electrochemical characterization of poly(eriochrome black T) modified glassy carbon electrode and its application to simultaneous determination of dopamine, ascorbic acid and uric acid," Electrochimica Acta, vol. 52, no. 20, pp. 6165-6171, 2007.

[20] X. Wang, N. Yang, Q. Wan, and X. Wang, "Catalytic capability of poly(malachite green) films based electrochemical sensor for oxidation of dopamine," Sensors and Actuators, B: Chemical, vol. 128, no. 1, pp. 83-90, 2007.

[21] J.-W. Mo and B. Ogorevc, "Simultaneous measurement of dopamine and ascorbate at their physiological levels using voltammetric microprobe based on overoxidized poly(1,2phenylenediamine)-coated carbon fiber," Analytical Chemistry, vol. 73, no. 6, pp. 1196-1202, 2001.

[22] T. Selvaraju and R. Ramaraj, "Electrocatalytic reduction of hydrogen peroxide at nanostructured copper modified electrode," Journal of Applied Electrochemistry, vol. 39, no. 3, pp. 321327, 2009.

[23] T. Selvaraju and R. Ramaraj, "Electrochemically deposited nanostructured platinum on Nafion coated electrode for sensor applications," Journal of Electroanalytical Chemistry, vol. 585, no. 2, pp. 290-300, 2005. 

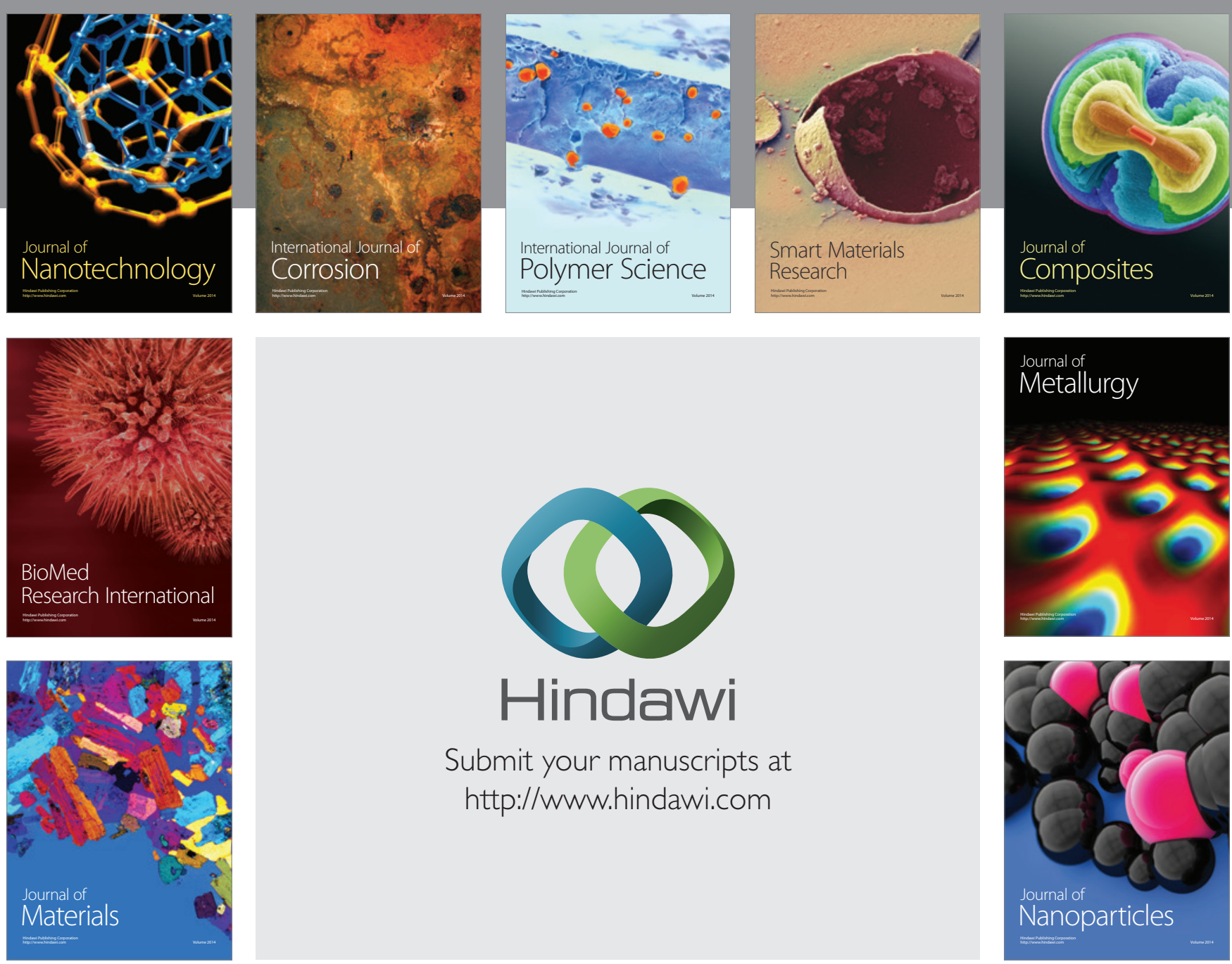

Submit your manuscripts at http://www.hindawi.com
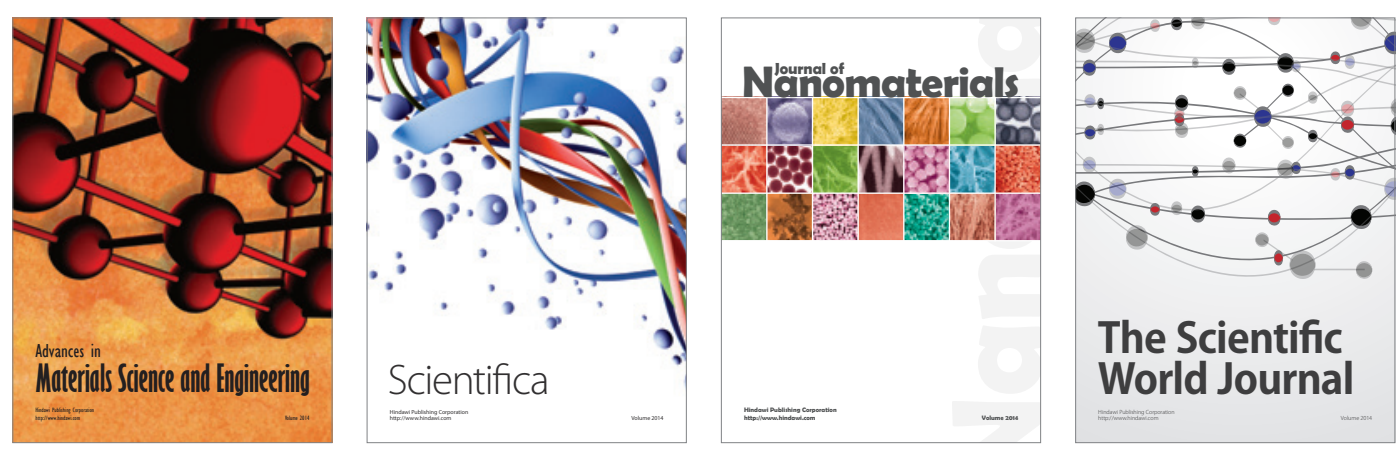

\section{The Scientific World Journal}
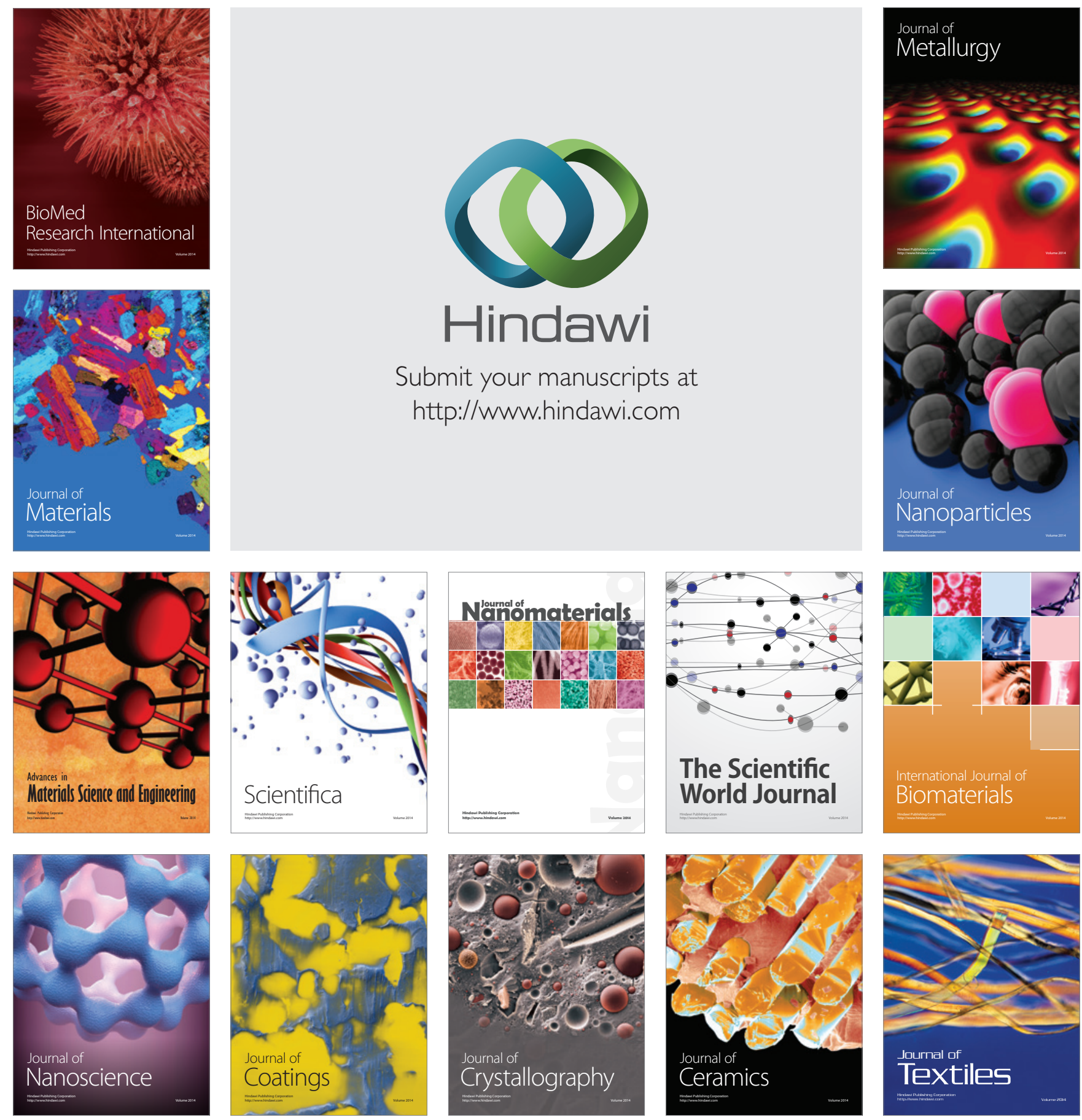